"This is the peer reviewed version of the following article: [Rosato, A. (2016), Selling substitute goods to loss-averse consumers: limited availability, bargains, and rip-offs. The RAND Journal of Economics, 47: 709-733. doi:10.1111/1756-2171.12139.], which has been published in final form at [doi: 10.1111/1756-2171.12139] This article may be used for non-commercial purposes in accordance with Wiley Terms and Conditions for Self-Archiving." 


\title{
Selling Substitute Goods to Loss-Averse Consumers: Limited Availability, Bargains and Rip-offs
}

\author{
Antonio Rosato* \\ University of Technology Sydney \\ Antonio.Rosato@uts.edu.au
}

January 11, 2016

\begin{abstract}
This article derives the optimal pricing and product-availability strategies for a retailer selling two substitute goods to loss-averse consumers and shows that limited-availability sales manipulate consumers into an ex-ante unfavorable purchase. The seller maximizes profits by raising the consumers' reference point through a tempting discount on a good available only in limited supply (the bargain) and cashing in with a high price on the other (the rip-off), which consumers buy if the bargain is not available in order to reduce their disappointment. The seller might prefer to offer a deal on the more valuable product, using it as a bait.
\end{abstract}

JEL classification: D11; D42; L11.

Keywords: Retail Pricing; Reference-Dependent Preferences; Loss Aversion; Limited Availability; Bait and Switch; Loss Leaders.

${ }^{*}$ This paper is a revised version of the first chapter of my doctoral dissertation submitted to UC Berkeley. I am indebted to Benjamin Hermalin, Botond Köszegi and, especially, Matthew Rabin for their invaluable advice and encouragement. I thank Ned Augenblick, Youssef Benzarti, Matthew Botsch, Kfir Eliaz, Joe Farrell, Shota Fujishima, Tristan GagnonBartsch, Fabian Herweg, Heiko Karle, Maciej Kotowski, Dan Levin, Takeshi Murooka, Ted O'Donoghue, Aniko Öry, Marco Ottaviani, Marco Pagnozzi, Alessandro Pavan, Nicola Pavoni, Vincenzo Pezone, Elio Rosato, Josh Schwartzstein, Massimo Scotti, Juan Carlos Suárez Serrato, Adam Szeidl, Felix Vàrdy, Miguel Villas-Boas and audiences at the 2012 Csef-Igier Symposium on Economics and Institutions in Anacapri, EconCon 2012 in Princeton, EARIE 2012 in Rome, University of Venice Ca' Foscari, SITE 2012, HP Labs in Palo Alto, UC Berkeley, ESSEC in Paris, University of Naples Federico II, Universitat Pompeu Fabra, University of Queensland, University of Technology Sydney, Florida State University and University of Utah for helpful comments and suggestions. Financial support from the Bank of Italy in the form of a scholarship entitled to Bonaldo Stringher is gratefully acknowledged. 
"One of the biggest problems during significant sale days like Black Friday is the deceptive practice of offering a popular, expensive item for a great sale price, but only stocking a very limited number of these products. This is somewhat of a bait-and-switch because even if that product is unavailable, you are likely to stay at the store and take advantage of other, less valuable sales."

— Denver Better Business Bureau (http://denver.bbb.org)

"Know why they call it "Black Friday?" It isn't because those sale items push retailers into the "black" (accounting speak for profitability). Those sale items are almost always loss leaders — items sold at a loss in order to lure you into the store in the hope you'll buy other, more profitable items. What really pushes retailers into the black are the profitable items you buy because you showed up at 4am and everything you hoped to buy was sold out and you HAD to buy SOMETHING."

— The Wisdom Journal (http://www.thewisdomjournal.com/Blog/beware-of-black-friday-bait-and-switch)

\section{Introduction}

Retailers often offer deals to attract consumers. In many cases, these deals apply only to selected products and are subject to "limited availability". Stores, for example, might advertise deals that are valid only "while supplies last," or they might offer price reductions on sale items only to the very first customers of the day. Consider, for instance, the deals that retailers offer on Black Friday, the day following American Thanksgiving, which marks the beginning of the Christmas shopping season in the US. As described by the opening quotes, on Black Friday retailers offer limited quantities of a popular, expensive product for a great sale price, but at the same time they have large stocks of other similar, substitute products available for a much higher price. ${ }^{1}$ Why, then, do stores discount only a few items heavily, and what is the reason for the dispersion, within the same store, in the price of similar goods? How do stores select which products to offer for a discount?

Traditional models of sales based on search costs are not well-equipped to answer these questions, as they mainly focus on price dispersion by single-product retailers either across venues (as in Salop and Stiglitz, 1977) or time (as in Varian, 1980), but do not look at product availability and within-store price dispersion across similar items. ${ }^{2}$

In this article, I develop a model of bait-and-switch in which a retailer offers limited-availability bargains to exploit consumers' loss-aversion and induce them to make an ex-ante unfavorable purchase. Specifically, building on Köszegi and Rabin (2006), I assume consumers' reference point for evaluating a purchase is given by their recent expectations about the purchase itself. With such preferences, expectations about price and likelihood of a purchase affect a consumer's willingness to pay for a good. For example, if a consumer expects to buy with high probability, he experiences a loss if he fails to buy. This, in turn, increases his willingness to pay. On the other hand, compared to the possibility

\footnotetext{
${ }^{1}$ Besides Black Friday, other examples of limited-availability sales in the U.S. are: (i) Cyber Monday, the first Monday after Thanksgiving Day, which mainly pertains to online shopping; (ii) Back-to-School Sales taking place at the end of summer; and (iii) the The Running of the Brides, a one-day sale of wedding gowns. Moreover, many big national retailers, like Target and Toys R Us, have begun to hold Black Friday-style sales during the summer as well.

${ }^{2}$ Rhodes (2015) and Zhou (2014) study multi-product search models when goods are complements. In Konishi and Sandfort (2002), a multi-product store can increase its profits by discounting only some of its products, even when they are substitutes. However, consumers in their model shop for a "search good" and they learn their tastes only once they arrive at the store.
} 
of getting a deal, paying a high price feels like a loss, which in turn decreases his willingness to pay. Because expectations about price and own future behavior are the reference point, the reference point is endogenously determined by imposing rational expectations: the (possibly stochastic) outcome implied by optimizing behavior conditional on expectations coincides with the agent's expectations.

The main contribution of the paper is to show that when two goods have similar value, the profitmaximizing strategy for the retailer is to offer a limited-availability deal on one good and extract consumer surplus via a high price on the other. Consumers perceive this deal as equivalent to a lottery over which good they will purchase and what price they will pay. The price of the good on sale (the bargain) is chosen such that it is not credible that consumers would not to buy it. Thus, the limitedavailability deal works as a bait in luring consumers into the store. ${ }^{3}$ Then, because consumers expect to make a deal with positive probability and dislike uncertainty in consumption outcomes, if the bargain is unavailable they prefer to buy the substitute good, even at a higher price (the rip-off). In other words, consumers go to the store enticed by the possibility of the bargain, but if it is not there they buy a substitute good as a means of reducing their disappointment. ${ }^{4}$ For this strategy to be effective, it is crucial that the bargain is available only in limited supply. In choosing the degree of availability, the seller faces the following trade-off. On the one hand, a high availability of the bargain makes consumers more attached to the idea of buying and this allows the seller to charge a higher price for the rip-off. On the other hand, a high availability of the bargain necessarily means less sales of the rip-off. Hence, when choosing the availability of the bargain the seller optimally balances these two effects.

According to current FTC regulation, it is not a bait-and-switch if the store communicates up-front that availability is limited. ${ }^{5}$ Nevertheless, the popular press and various consumer associations perceive limited-availability deals to be exploitative, suggesting that among the consumers who chase such deals, some fulfill their goal and get a bargain while others, however, might instead buy a different and often not-on-sale item. ${ }^{6}$ By assuming that the seller publicly announces (and commits to) availability, my model considers the most favorable environment for consumers not to be exploited by a bait-and-switch strategy; yet I show that from an ex-ante perspective, i.e. before the reference point is formed, they would be better off committing to never buying rather than following their equilibrium strategy of buying the expensive substitute. This happens because with expectations-based reference-dependent preferences the seller can manipulate consumers' participation constraint with her own strategy. The intuition is as follows: if a consumer expects to find a product he likes available for a very low price, he will plan to definitely buy it if available. This attachment, however, changes his reference point. If the store runs out of the bargain, but has a substitute available for a higher price, the consumer must now choose between a loss of money from paying a higher price and a loss of consumption from returning home empty-handed. While, in equilibrium, buying the expensive substitute is indeed the best response

\footnotetext{
${ }^{3}$ Indeed, in Black Friday jargon these deals are called "doorbusters."

${ }^{4}$ Because of loss aversion, consumers are willing to pay a premium in order to reduce the feeling of loss resulting from not getting the bargain. This is in contrast to models with overconfident or naïve consumers, as in DellaVigna and Malmendier (2004), Eliaz and Spiegler (2006, 2008, 2011), Gabaix and Laibson (2006) and Grubb (2009).

${ }^{5}$ The current FTC Guides Against Bait Advertising require retailers "to have available at all outlets listed in the advertisement a sufficient quantity of the advertised product to meet reasonably anticipated demands, unless the advertisement clearly and adequately discloses that supply is limited" (16 C.F.R. Part 238.3).

${ }^{6}$ Empirical studies in marketing and psychology show that consumers are likely to buy substitute items if their preferred product is out of stock, and even more so if the product they were planning to buy was on sale or if the seller had announced up-front that quantities were limited. I review the evidence about consumers' response to stockouts in Section 2.
} 
to his expectations, it is still worse than if he could have prevented the feeling of loss by avoiding the expectation of getting the bargain in the first place. Hence, even though with some probability they get a good deal, on average consumers are hurt by limited-availability bargain sales. Thus, the current FTC Guides Against Bait Advertising, by allowing stores to credibly announce that they have limited supplies for bargain items, might have the perverse effect of reducing consumers' welfare.

I also show that despite the products being substitutes, loss aversion endogenously induces a positive demand spillover so that the higher a consumer's intrinsic valuation for a product, the higher is his willingness to pay for a substitute of that product. Furthermore, if the goods are vertically differentiated, the seller may use the more valuable product as the bargain. This may, at first, seem odd, given that consumers are (intrinsically) willing to pay a higher price for the superior good. Yet, exactly because consumers value this item more, the possibility of getting it for a bargain makes them feel a larger loss, in terms of forgone consumption, when this item is not available; hence, they are willing to pay a lot to avoid (or mitigate) this loss, which, in turn, allows the seller to charge a higher price for the rip-off. Hence, my model predicts that more valuable products are more likely used as baits.

Another implication of the model is that a seller, in order to effectively induce uncertainty into the consumers' plans, may introduce a less socially desirable or, worse, socially wasteful product and hence that the profit-maximizing product line could differ from the socially optimal one. ${ }^{7}$ Furthermore, the bargain item can be a "loss leader" (i.e., being priced below cost). Traditional models of consumer behavior can explain the use of loss leaders for complement goods (see Ambrus and Weinstein, 2008); my model instead rationalizes the use of loss leaders for substitutes. ${ }^{8}$ With classically assumed referencefree preferences, the scope for using loss leaders is to increase store traffic; however, for this increase in store traffic to be profitable, consumers must buy other items in addition to the loss leader. In my model, instead, loss leaders lure consumers into the store, but their profitability stems from the fact that, if the seller has run out of the loss-leading product, consumers will buy another item instead of the loss leader in order to minimize their disappointment. Moreover, while traditional models of loss leaders (e.g., Hess and Gerstner, 1987 and Lal and Matutes, 1994) suggest that products with lower reservation prices are more natural candidates to be loss leaders, my model explains the use of highly valuable products as loss leaders. ${ }^{9}$ This is consistent with the observation that, on Black Friday, Best Buy offers a below-cost large-screen flat TV to the first ten people who buy one.

Related Literature. This article joins a recent literature on how firms respond to consumer loss aversion. Heidhues and Köszegi (2008), Karle and Peitz (2014) and Zhou (2011) study the implications of loss aversion in oligopolistic markets with differentiated products. While these contributions focus on informative advertising and price dispersion (or lack thereof) across stores, the focus of my paper instead is on manipulative advertising and within-store price variation. ${ }^{10}$

\footnotetext{
${ }^{7}$ Klemperer and Padilla (1997) obtain a similar result in an oligopoly model where consumers have classical preferences and multi-unit demand. For this environment they show that a firm might want to introduce an additional, socially wasteful variety, because of a profitable business stealing effect.

${ }^{8}$ In and Wright (2014) propose a theory of loss-leader pricing based on the idea that firms competing à la Bertrand offer below-cost prices on some items to signal that their other substitute items are not priced too high.

${ }^{9}$ Kamenica (2008) proposes a model of contextual inference from product lines where a firm may try to manipulate consumers' beliefs by introducing premium loss leaders - expensive goods of overly high quality that increase the demand for other goods.

${ }^{10}$ Carbajal and Ely (forthcoming) and Hahn et al. (2015) study screening with loss-averse consumers. Karle (2014)
} 
My paper is most related to Heidhues and Köszegi (2014). In their model, a single-product monopolist maximizes profits by committing to a stochastic price strategy made of low, variable sales prices and a high, sticky regular price. My paper complements theirs by showing that the intuition behind their result applies also to price variation across multiple (substitute) goods and further extends this intuition to derive new results about the inefficiencies that loss aversion creates for the design of product lines and product development, as well as new predictions about what products stores put on sale. If the two goods are perfect substitutes and have equal marginal costs, my model coincides with a special case of theirs in which the monopolist uses a two-price distribution. However, my model makes clear predictions about the price of the two items and their supply level; whereas in their model, Heidhues and Köszegi (2014) are unable to characterize the probability of the seller holding a sale and her non-sale prices. Moreover, in Heidhues and Köszegi (2014) the seller has to be able to commit to an entire price distribution in advance; in my model, instead, the seller only needs to announce two prices, one for each good; yet, consumers still face uncertainty in my model because the item on sale is subject to limited availability. Relatedly, in my model the seller can credibly advertise that she is having a sale on selected products - as stores often do - whereas in their model the seller can only advertise that there might be a sale with some probability. Finally, from a purely theoretical perspective, Heidhues and Köszegi's (2014) main contribution is to show that it can be profitable for a firm to introduce risk in an otherwise deterministic environment in order to exploit the time inconsistency of expectations-based loss-averse agents; yet, previous studies - like Heidhues and Köszegi (2008), Herweg et al. (2010), Spiegler (2012) and Herweg and Mierendorff (2013) — have shown that it is optimal for firms to insure loss-averse consumers against exogenous uncertainty. My model is able to reconcile these seemingly contradicting results by showing that uncertainty in consumption and uncertainty in price are inversely related. If the products are similar, the seller has more freedom in pricing them apart and maximizes profits by doing so; if instead the products are very different, the seller wants to reduce consumers' uncertainty in consumption by pricing them closely.

Within the realm of industrial organization, this paper is closely related to the literature on baitand-switch and loss leaders. Lazear (1995) studies a duopoly with differentiated goods in which each firm produces only one good and derives the conditions for bait-and-switch to be profitable. However, in his model bait-and-switch is purely false advertising as a firm claims to sell a different good than the one it actually produces. In my model, instead, the firm is not lying to the consumers but is using a truthful version of bait-and-switch by endogenously limiting availability. Furthermore, in Lazear (1995) prices are exogenous whereas in mine they are optimally chosen by the seller. Gerstner and Hess (1990) present a model of bait-and-switch in which retailers advertise only selected brands, lowpriced advertised brands are understocked and in-store promotions are biased towards more expensive substitute brands. In their model, like mine, consumers are rational and foresee stockouts. However, they assume that in-store promotions create a permanent utility boost so that, in equilibrium, some consumers will switch to more expensive brands. Eliaz and Spiegler (2011) propose a model where stores compete for consumers' limited attention by expanding their product lines with "pure attention grabbers"; that is, loss-leading products whose sole purpose is to attract consumers' attention to the other products in the store. Once in the store, a consumer may realize that there is another product analyzes the advertising strategy of a monopolist selling to loss-averse consumers who are uncertain about their tastes. 
that better suits his needs. Thus, differently from my model, a consumer might switch to a product with a higher margin even if the bargain item is available.

Models of price dispersion under demand uncertainty (Dana, 1999, 2001; Deneckere and Peck, 1995) and buying frenzies (De Graba, 1995; Gilbert and Klemperer, 2000) also show that rationing consumers through intentional stockouts can be a profitable strategy. However, these models apply mainly to products that are launched on the market for the first time and for which either the seller or the consumers cannot predict what the actual demand will be. Yet, goods sold during sales are usually not appearing on the market for the first time. Moreover, in these models once the true demand state is revealed, the scope for rationing disappears; in my model, instead, the scope for rationing arises directly from the consumers' preferences.

Finally, Thanassoulis (2004) considers a monopolist selling two substitute goods to risk-neutral consumers with unit demand, and derives conditions such that the optimal tariff includes lotteries. In my model, when the seller endogenously reduces availability, from the consumers' point of view this is equivalent to a lottery. Nevertheless, there are several differences between the models. First, my result on the optimality of limited-availability deals holds also when consumers are homogeneous, whereas his result on the optimality of lotteries does not. Second, in his lotteries the uncertainty is only on the good dimension but not on the price one, whereas in my case it is on both dimensions. Last, in his model a lottery is offered in addition to each good being offered in isolation with its own posted price; in my model instead each good is offered in isolation with its own price, but because availability is limited, consumers are uncertain about what they will purchase.

The paper proceeds as follows. Section 2 briefly summarizes the key empirical evidence on sales and stockouts. Section 3 describes the model and the solution concept. Section 4 presents the main result about optimal pricing and availability. Section 5 considers various extensions of the main model. Section 6 concludes by recapping the results of the model and pointing out some of its limitations as well as possible avenues for future research.

\section{Evidence on Sales and Stock-Outs in Retailing}

Sales, in the sense of periodic, temporary price reductions, are a ubiquitous feature of retail pricing (see Hosken and Reiffen, 2004a and Nakamura and Steinsson, 2008). However, among all the items supermarkets and other retailers carry, usually only a small fraction each week are offered at a low sale price and, within categories, retailers seem to systematically place some products on sale more often than others, with more popular items being more likely to go on sale (Hosken and Reiffen, 2004b). According to a study by ShopAdvisor, from Nov. $1^{\text {st }}$ through Dec. $24^{\text {th }} 2011$, the day with the lowest percentage $(46 \%)$ of products on sale below their initial holiday season price was indeed Black Friday, Nov. $25^{t h}$. In fact, Black Friday is also the day on which shoppers begin to see prices spike on selected items: on Black Friday itself, $24 \%$ of the toys on ShopAdvisor's list were priced above their initial holiday season price. Chevalier, Kashyap and Rossi (2003) find that the majority of sales are not caused by changes in wholesale pricing, implying therefore that sales are primarily due to changes in retailers' margins.

While not as ubiquitous as sales, stockouts are also prevalent in retailing. Gruen et al. (2002) 
report an $8.3 \%$ out-of-stock rate worldwide, rising to even $25 \%$ for some promoted items. Hess and Gerstner (1987) sampled two general merchandise stores and found that stockouts occurred more often for products on sale than for similar products not on sale. Similarly, Taylor and Fawcett (2001) investigated availability of advertised products for three large national mass merchants, four category killers involved in the office supplies and electronics subcategories and three retail grocers in the MidWest, and found that the stock-out rate for advertised items was twice as high as that of comparable, non-advertised items. Bils (2004) presents evidence on temporary stockouts for durable consumer goods using data from the CPI Commodities and Services Survey and finds that from January 1988 to June 2004 the temporary stockout rate averaged between $8.8 \%$ and $9.2 \%$.

Several marketing and psychology studies on consumers' response to product unavailability show that consumers are often willing to buy substitute items when faced with stockouts. Depending on the specific characteristics of the product and store under study, the percentage of consumers who is willing to buy a substitute - within the same store — ranges from $30 \%$ to $80 \%$; see, for example, Emmelhainz et al. (1991), Anupindi et al. (1998), Fitzsimons (2000) and Diels et al. (2013). ${ }^{11}$ Through a postpurchase questionnaire, Zinn and Liu (2001) find also that consumers are more likely to leave a store empty-handed if they are surprised by the stockout; this finding suggests that prior expectations of product availability may be an important predictor of out-of-stock response. Relatedly, Anderson et al. (2006) find that consumers are more willing to buy a substitute if the stockout product was on sale or if limited supplies were announced up-front. Conlon and Mortimer (2011) conducted a field experiment by exogenously removing top-selling products from a set of vending machines and tracking subsequent consumer responses. Their results show that most consumers purchase another good when a top-selling product is removed. ${ }^{12}$ Moreover, some product removals increased the vendor's profits as consumers substituted towards products with higher margins.

\section{Model}

There is a unit mass of identical consumers whose intrinsic valuation for good $i$ is $v_{i}, i=1,2$. Let $v_{1} \geq v_{2}>0$. The goods are substitutes and consumers want to buy at most one unit of one good.

Following Köszegi and Rabin (2006), a consumer's (his) utility function has two components. First, when buying item $i$ at price $p_{i}$, a consumer experiences consumption utility $v_{i}-p_{i}$. Second, a consumer also derives utility from the comparison of his actual consumption to a reference point given by his recent expectations (probabilistic beliefs). ${ }^{13}$ For a riskless consumption outcome $\left(v_{i}, p_{i}\right)$ and riskless expectations $\left(v^{r}, p^{r}\right)$, a consumer's total utility is given by

$$
U\left[\left(v_{i}, p_{i}\right) \mid\left(v^{r}, p^{r}\right)\right]=v_{i}-p_{i}+\mu\left(v_{i}-v^{r}\right)+\mu\left(p^{r}-p_{i}\right)
$$

\footnotetext{
${ }^{11}$ Although product availability is probably more relevant for traditional brick and mortar stores, Jing and Lewis (2011) and Kim and Lennon (2011) show that limited-availability sales and stockouts pertain to online retailers as well. Relatedly, Ellison and Ellison (2009) analyze data from Pricewatch, an online price comparison site popular with savvy computer-parts shoppers and conclude that bait-and-switch is an effective marketing strategy also for online retailers.

${ }^{12}$ In the field experiment of Conlon and Mortimer (2011), given that the products are snacks, hunger has most likely played a role in pushing consumers to purchase a substitute product.

${ }^{13}$ Recent experimental evidence lends support to Köszegi and Rabin (2006)'s model of reference-dependent preferences; see for instance Abeler et al. (2011), Ericson and Fuster (2011), Gill and Prowse (2012) and Karle et al. (2015).
} 
where

$$
\mu(x)=\left\{\begin{array}{cl}
\eta x & \text { if } \quad x \geq 0 \\
\eta \lambda x & \text { if } \quad x<0
\end{array}\right.
$$

is gain-loss utility. The parameter $\eta>0$ is the weight a consumer attaches to gain-loss utility, and $\lambda>1$ is the coefficient of loss aversion. By positing a constant marginal utility from gains and a constant, but larger marginal disutility from losses, this formulation captures prospect theory's (Kahneman and Tversky, 1979; Tversky and Kahneman, 1991) loss aversion, but without its diminishing sensitivity. ${ }^{14}$

According to (1), a consumer assesses gains and losses separately over product's quality and money. For instance, if his reference point is that he will not get the product (and thus pay nothing), then he evaluates getting the product and paying for it as a gain in the product dimension and a loss in the money dimension rather than as a single gain or loss. This is consistent with much of the experimental evidence commonly interpreted in terms of loss aversion. ${ }^{15}$

Because in many situations expectations are stochastic, Köszegi and Rabin (2006) extend the utility function in (1) to allow for the reference point to be a pair of probability distribution $F=\left(F^{v}, F^{p}\right)$ over the two dimensions of consumption utility. In this case a consumer's total utility from the outcome $\left(v_{i}, p_{i}\right)$ can be written as

$$
U\left[\left(v_{i}, p_{i}\right) \mid\left(F^{v}, F^{p}\right)\right]=v_{i}-p_{i}+\int_{v^{r}} \mu\left(v_{i}-v^{r}\right) d F^{v}\left(v^{r}\right)+\int_{p^{r}} \mu\left(p^{r}-p_{i}\right) d F^{p}\left(p^{r}\right) .
$$

In words, when evaluating $\left(v_{i}, p_{i}\right)$ a consumer compares it to each possible outcome in the reference lottery. For example, if he had been expecting to buy good 1 for $\$ 15$, then buying good 2 for $\$ 10$ feels like a loss of $v_{1}-v_{2}$ on the product dimension and a gain of $\$ 5$ on the money dimension. ${ }^{16}$ Similarly, if a consumer had been expecting to buy good 1 for either $\$ 10$ or $\$ 20$, then paying $\$ 15$ for it feels like a loss of $\$ 5$ relative to the possibility of paying $\$ 10$, and like a gain of $\$ 5$ relative to the possibility of paying $\$ 20$. In addition, the weight on the loss (gain) in the overall experience is equal to the probability with which he had been expecting to pay $\$ 10(\$ 20)$.

Following Köszegi and Rabin (2006), I assume that beliefs are rational: a consumer correctly anticipates the implications of his plans, and makes the best plan he knows he will carry through. Notice that any plan of behavior induces some expectations. If, given these expectations, a consumer is not willing to follow the plan, then he could not have rationally formulated the plan in the first place. Hence, a credible plan must have the property that it is optimal given the expectations it generates.

Formally, let $H \in[0,1]^{2} \times \mathbb{R}_{+}^{2}$ denote a consumer's expectations, induced by the seller's strategy, about the availability and the price of each product. Consumers choose one of five possible plans: "never buy," "if item 1 is available, buy it; otherwise don't buy," "if item 2 is available, buy it; otherwise don't buy," "if item 1 is available, buy it; otherwise buy item 2 (if it is available)," and "if item 2 is available,

\footnotetext{
${ }^{14}$ Köszegi and Rabin (2006) allow for gain-loss utility to be non-linear to capture diminishing sensitivity. For simplicity, I only focus on loss aversion.

${ }^{15}$ This feature can explain the endowment effect observed in many laboratory experiments (see Kahneman et al. 1990, 1991). The common explanation of the endowment effect is that owners feel giving up an object as a painful loss that counts more than the money they receive in exchange.If gains and losses were defined over the value of the entire transaction, owners would not be more sensitive to giving up the object than to receiving money in exchange.

${ }^{16}$ Therefore, the two goods are substitutes not only in the usual sense, but also in the sense of being evaluated along the same hedonic dimension.
} 
buy it; otherwise buy item 1 (if it is available)." Let $\sigma: H \rightarrow\{\{\varnothing\},\{1, \varnothing\},\{2, \varnothing\},\{1,2\},\{2,1\}\}$ denote a consumer's plan and let $\Gamma_{H, \sigma}$ be the distribution over final consumption outcomes induced jointly by $H$ and $\sigma$. In a personal equilibrium the behavior generating expectations must be optimal given the expectations:

Definition $1 \sigma$ is a Personal Equilibrium (PE) if, for each possible realization of availability of the goods,

$$
U\left[\sigma \mid \Gamma_{H, \sigma}\right] \geq U\left[\sigma^{\prime} \mid \Gamma_{H, \sigma}\right]
$$

for any $\sigma^{\prime} \neq \sigma$.

If there exist multiple personal equilibria, a consumer selects the one that maximizes his expected utility from an ex-ante perspective:

Definition $2 \sigma$ is a Preferred Personal Equilibrium (PPE) if it is a PE and

$$
E U_{\Gamma_{H, \sigma}}\left[\sigma \mid \Gamma_{H, \sigma}\right] \geq E U_{\Gamma_{H, \sigma^{\prime}}}\left[\sigma^{\prime} \mid \Gamma_{H, \sigma^{\prime}}\right]
$$

for any $\sigma^{\prime}$ such that $\sigma^{\prime}$ is a PE.

The seller (she) is a monopolist. The marginal cost of product $i$ is $c_{i} \geq 0, i=1,2$. There are no fixed costs. Let $\sigma^{*}(H)$ denote consumers' PPE for a given choice of prices and availability by the seller. Correctly anticipating how her strategy affects consumers' plans, the seller chooses the price pair $\left(p_{1}, p_{2}\right) \in \mathbb{R}_{+}^{2}$ and quantity pair $\left(q_{1}, q_{2}\right) \in[0,1]^{2}$ that solve the following maximization problem:

$$
\begin{aligned}
\max _{q_{1}, q_{2}, p_{1}, p_{2}} \pi\left(p_{1}, p_{2}, q_{1}, q_{2} ; c_{1}, c_{2}\right)=q_{1}\left(p_{1}-c_{1}\right)+q_{2}\left(p_{2}-c_{2}\right) \\
\text { s.t. } E U_{\Gamma_{H, \sigma^{*}(H)}}\left[\sigma^{*}(H) \mid \Gamma_{H, \sigma^{*}(H)}\right] \geq E U_{\Gamma_{H, \sigma^{\prime}}}\left[\sigma^{\prime} \mid \Gamma_{H, \sigma^{\prime}}\right] .
\end{aligned}
$$

For $i=1,2$, if $q_{i}<1$, then $\operatorname{good} i$ is subject to "limited availability" so that only a fraction $q_{i}$ of the consumers can purchase it. I assume that, in the event of a stockout, rationing is proportional: each consumer has the same ex-ante probability of obtaining the good, which is allocated to consumers on a random first-come, first-serve basis. ${ }^{17}$ The interaction between the monopolist and the consumers lasts two periods, 0 and 1 . In period 0 , the seller announces (and commits to) a price and an availability level for each product; after observing the seller's choice of quantities and prices, consumers pick the plan that is consistent and that maximizes their expected utility (PPE). ${ }^{18}$ Consumers cannot commit to a plan ex-ante. ${ }^{19}$ In period 1, consumers execute their plans. For technical and expositional reasons,

\footnotetext{
${ }^{17}$ There are two possible interpretations of limited availability in my model. One way is to look at it as a lottery that the seller offers and that is realized independently for each consumer. The second way we can think of limited availability is by using a rationing rule. In this case the seller is announcing two "supply levels", one for good 1, $q_{1}$ and one for good $2, q_{2}$ and consumers can choose which item to buy among the ones they find available when they enter the store. Under this latter interpretation, $q_{i}$ should be thought of as the "the number of units" available of good $i$.

${ }^{18}$ The assumption about the seller announcing both prices in period 0 is not very realistic because although stores frequently advertise their deals, it is rather uncommon to see a store publicizing its high prices. However, in online Appendix C I show that the main results of the paper are unchanged if the seller commits only to the price of the bargain.

${ }^{19}$ That is, the solution concept is unacclimating personal equilibrium (UPE) and not choice-acclimating personal equilibrium (CPE); see Köszegi and Rabin (2007).
} 
I assume that consumers always break indifference in favor of buying. This assumption ensures that the seller' s maximization problem is well-defined and that there are no personal equilibria in mixed strategies (see also Köszegi and Rabin, 2006 and Heidhues and Köszegi, 2014).

An Illustrative Example. Consider a monopolist supplying two goods, 1 and 2, to consumers who have expectations-based reference-dependent preferences with $\eta=1$ and $\lambda=3$. Let $v_{1}=v, v_{2}=\frac{2}{3} v$, $c_{1}=\frac{3}{5} v$ and $c_{2}=\frac{v}{3}$, with $v>0$. If she had to provide full availability, the seller would supply only item 1 and price it at $v$, obtaining a profit of $\frac{2}{5} v$.

Consider instead the following limited-availability scheme: $q_{1}=\frac{1}{4}, q_{2}=\frac{3}{4}, p_{1}=\frac{v}{2}$ and $p_{2}=v$. First, notice that at these prices plan $\{\varnothing\}$ is not a PE for the consumers. If they plan to buy nothing and follow through their plan, their utility is

$$
U[(0,0) \mid\{\varnothing\}]=0 .
$$

However, such a plan is not credible for the consumers because if they deviate and buy item 1 (if they find it available) their utility is

$$
U\left[\left(v_{1}, p_{1}\right) \mid\{\varnothing\}\right]=\underbrace{\frac{v}{2}+v-3\left(\frac{v}{2}\right)}_{v_{1}-p_{1}+\eta v_{1}-\eta \lambda p_{1}}=0 .
$$

As consumers break indifference in favor of buying, then they will deviate and buy the item. Intuitively, the price of item 1 is so low that if consumers had planned not to buy it, then if item 1 is indeed available, they would like to surprise themselves and buy it, and as the price is very low, the gain on the product dimension outweighs the loss on the money dimension.

Next, we have that plan $\{1, \varnothing\}$ - planning to buy item 1 if available and to buy nothing otherwise - is a PE as

$$
\begin{aligned}
U\left[\left(v_{1}, p_{1}\right) \mid\{1, \varnothing\}\right] & =\underbrace{\frac{v}{2}+v\left(\frac{3}{4}\right)-3\left(\frac{v}{2}\right)\left(\frac{3}{4}\right)}_{v_{1}-p_{1}+\eta v_{1}\left(1-q_{1}\right)-\eta \lambda p_{1}\left(1-q_{1}\right)} \\
& >\underbrace{-3 v\left(\frac{1}{4}\right)+\left(\frac{v}{2}\right)\left(\frac{1}{4}\right)}_{-\eta \lambda v_{1} q_{1}+\eta p_{1} q_{1}}=U[(0,0) \mid\{1, \varnothing\}]
\end{aligned}
$$

and

$$
\begin{aligned}
U[(0,0) \mid\{1, \varnothing\}] & =\underbrace{-3 v\left(\frac{1}{4}\right)+\left(\frac{v}{2}\right)\left(\frac{1}{4}\right)}_{-\eta \lambda v_{1} q_{1}+\eta p_{1} q_{1}} \\
& >\underbrace{-\frac{v}{3}+\frac{2}{3} v\left(\frac{3}{4}\right)-3\left(\frac{v}{3}\right)\left(\frac{1}{4}\right)-3 v\left(\frac{3}{4}\right)-3\left(\frac{v}{2}\right)\left(\frac{1}{4}\right)}_{v_{2}-p_{2}+\eta v_{2}\left(1-q_{1}\right)-\eta \lambda\left(v_{1}-v_{2}\right) q_{1}-\eta \lambda p_{2}\left(1-q_{1}\right)-\eta \lambda\left(p_{2}-p_{1}\right) q_{1}}=U\left[\left(v_{2}, p_{2}\right) \mid\{1, \varnothing\}\right] .
\end{aligned}
$$

That is, if item 1 is available, consumers will follow their plan and buy it; however, if item 1 is 
not available they will prefer to buy nothing over buying item $2 .{ }^{20}$ Intuitively, if consumers enter the store expecting to consume item 1 with positive probability and item 1 is available, they are willing to follow their plan as the price of item 1 is relatively low compared to its intrinsic value; however, they are not willing to buy item 2 if they were not expecting to do so as the price of item 2 is relatively high compared to its intrinsic value. Similarly, plan $\{1,2\}$ is also a PE as

$$
\begin{aligned}
U\left[\left(v_{1}, p_{1}\right) \mid\{1,2\}\right] & =\underbrace{\frac{v}{2}+\left(\frac{v}{3}\right)\left(\frac{3}{4}\right)+\left(\frac{v}{2}\right)\left(\frac{3}{4}\right)}_{v_{1}-p_{1}+\eta\left(v_{1}-v_{2}\right) q_{2}+\eta\left(p_{2}-p_{1}\right) q_{2}} \\
& >\underbrace{-\frac{v}{3}-3\left(\frac{v}{3}\right)\left(\frac{1}{4}\right)-3\left(\frac{v}{2}\right)\left(\frac{1}{4}\right)}_{v_{2}-p_{2}-\eta \lambda\left(v_{1}-v_{2}\right) q_{1}-\eta \lambda\left(p_{2}-p_{1}\right) q_{1}}=U\left[\left(v_{2}, p_{2}\right) \mid\{1,2\}\right]
\end{aligned}
$$

and

$$
\begin{aligned}
U\left[\left(v_{2}, p_{2}\right) \mid\{1,2\}\right] & =\underbrace{-\frac{v}{3}-3\left(\frac{v}{3}\right)\left(\frac{1}{4}\right)-3\left(\frac{v}{2}\right)\left(\frac{1}{4}\right)}_{v_{2}-p_{2}-\eta \lambda\left(v_{1}-v_{2}\right) q_{1}-\eta \lambda\left(p_{2}-p_{1}\right) q_{1}} \\
& >\underbrace{-3 v\left(\frac{1}{4}\right)-3\left(\frac{2}{3} v\right)\left(\frac{3}{4}\right)+\frac{v}{2}\left(\frac{1}{4}\right)+v\left(\frac{3}{4}\right)}_{-\eta \lambda v_{1} q_{1}-\eta \lambda v_{2} q_{2}+\eta p_{1} q_{1}+\eta p_{2} q_{2}}=U[(0,0) \mid\{1,2\}] .
\end{aligned}
$$

The intuition is that, by planning to always buy something, consumers expect to enjoy at least $v_{2}$ for sure; because of this attachment effect, therefore, they are willing to buy item 2 when they were expecting to do so even if its price is relatively high. Furthermore, plan $\{1,2\}$ is the PPE as

$$
\begin{aligned}
E U[\{1,2\} \mid\{1,2\}] & =\underbrace{\frac{1}{4}\left(\frac{v}{2}\right)+\frac{3}{4}\left(-\frac{v}{3}\right)-\frac{6}{16}\left(\frac{v}{3}\right)-\frac{6}{16}\left(\frac{v}{2}\right)}_{q_{1}\left(v_{1}-p_{1}\right)+q_{2}\left(v_{2}-p_{2}\right)-\eta(\lambda-1) q_{1} q_{2}\left(v_{1}-v_{2}\right)-\eta(\lambda-1) q_{1} q_{2}\left(p_{2}-p_{1}\right)} \\
& =\underbrace{\frac{1}{4}\left(\frac{v}{2}\right)-\frac{6}{16}\left(v+\frac{v}{2}\right)}_{\left.q_{1}-p_{1}\right)-\eta(\lambda-1) q_{1}\left(1-q_{1}\right)\left(v_{1}+p_{1}\right)}=E U[\{1, \varnothing\} \mid\{1, \varnothing\}] .
\end{aligned}
$$

The reason why, from an ex-ante point of view, consumers prefer plan $\{1,2\}$ over plan $\{1, \varnothing\}$ is that this plan reduces the magnitude of the fluctuations in their consumption outcomes and, therefore, makes them subject to a smaller expected gain-loss disutility. Finally, notice that with this limited-availability scheme the seller's profit equals $\frac{19}{40} v$, which is higher than the profit under full availability.

This example illustrates already many of the key insights of the general model. First, with a limited-availability scheme the seller is able to obtain a higher profit than what she can obtain with full availability. The prices of the bargain and the rip-off are chosen by the seller in a way such that (i) plan $\{\varnothing\}$ is not a PE for the consumers and (ii) plan $\{1,2\}$ is the consumers' PPE. Furthermore, the superior item is used as the bargain and it is priced below its marginal cost. Next section formalizes and generalizes these insights.

\footnotetext{
${ }^{20}$ Notice that $U\left[\left(v_{1}, p_{1}\right) \mid\{1, \varnothing\}\right]>U[(0,0) \mid\{1, \varnothing\}]$ and $U[(0,0) \mid\{1, \varnothing\}]>U\left[\left(v_{2}, p_{2}\right) \mid\{1, \varnothing\}\right]$ readily imply that $U\left[\left(v_{1}, p_{1}\right) \mid\{1, \varnothing\}\right]>U\left[\left(v_{2}, p_{2}\right) \mid\{1, \varnothing\}\right]$ so that a consumer will never deviate and buy item 2 if item 1 is available.
} 


\section{Optimal Availability and Pricing}

In this section I derive the seller's profit-maximizing strategy. In order to simplify the exposition and reduce the number of cases to consider, I make the following assumptions:

Assumption $1 v_{1}-c_{1} \geq v_{2}-c_{2}$.

Assumption $2 \frac{v_{2}}{v_{1}}>\max \left\{\frac{1+\eta \lambda}{2+\eta \lambda+\eta}, \frac{1+\eta}{1+\eta \lambda}\right\}$.

Assumption 1 says that good 1 is not only the one that consumers like the most, but also the one with a (weakly) higher social value. ${ }^{21}$ Assumption 2 restricts how strong consumers' preference for good 1 over good 2 can be by requiring that $v_{1}$ and $v_{2}$ are not too far apart. ${ }^{22}$

If consumers were not loss-averse, the profit-maximizing strategy for the seller would be to just set $p_{i}=v_{i}$, for $i=1,2$, and $q_{1}=1$. Consumers would get zero surplus and the seller's profit would be exactly $v_{1}-c_{1}$. Yet, with loss-averse consumers the seller can attain higher profits by offering a limited-availability deal on one item and raising the price of the other.

If product $i \in\{1,2\}$ is used as a bargain, then its price must equal $p_{i}^{\min } \equiv \frac{1+\eta}{1+\eta \lambda} v_{i}$ as this is the highest price that makes $\{\varnothing\}$ not a credible plan for the consumers (see Köszegi and Rabin, 2006). In this way the seller modifies consumers' outside option and leaves them with only two possible credible strategies: planning to buy only the bargain (and nothing otherwise) or planning to buy the bargain if available and the rip-off otherwise. By realizing that they will always buy the bargain (if available), however, consumers become subject to an "attachment effect" which allows the seller to charge a high price for the rip-off. Furthermore, it is in the seller's best interest that consumers expect to buy one good for sure; that is, the market is fully covered so that $q_{1}+q_{2}=1 .^{23}$ Hence, I will hereafter use $q$ and $1-q$ to denote the availability of good 1 and good 2 , respectively.

The seller wants consumers to plan to always buy by selecting either plan $\{1,2\}$ or plan $\{2,1\}$. Yet it is not optimal for her to choose a rip-off price such that always buying is the unique consistent plan. Instead, by exploiting consumers' dislike for uncertainty, the seller can raise the price of the rip-off up to the point where consumers are indifferent, in period 0, between planning to buy only the bargain (and nothing otherwise) and planning to buy the bargain if available and the rip-off otherwise. Hence, the optimal price for the rip-off item is the one that makes always buying the consumers' PPE. Moreover, as the following lemma shows, the price of the rip-off depends on the choice of the bargain item. ${ }^{24}$

Lemma 1 If the seller uses item 2 as the bargain (i.e., $p_{2}=p_{2}^{\min }$ ), then the optimal price for good 1 is

$$
p_{1}^{*}=v_{1}+\frac{2(1-q) \eta(\lambda-1)\left[v_{2}(2+\eta+\eta \lambda)-v_{1}(1+\eta \lambda)\right]}{(1+\eta \lambda)[1+\eta(\lambda-1)(1-q)]}
$$

If instead she uses item 1 as the bargain (i.e., $p_{1}=p_{1}^{\min }$ ), then the optimal price for good 2 is

$$
p_{2}^{*}=v_{2}+\frac{2 q v_{1} \eta(\lambda-1)(1+\eta)}{(1+\eta \lambda)[1+\eta(\lambda-1) q]} .
$$

\footnotetext{
${ }^{21}$ The analysis for the case $v_{1}-c_{1}<v_{2}-c_{2}$ is similar, the only difference being that the seller always uses item 1 as the bargain. Details are available from the author upon request.

${ }^{22}$ For the analysis when Assumption 2 fails, see Online Appendix D.

${ }^{23}$ See Lemma 3 in Appendix A.

${ }^{24}$ All proofs appear in the appendices.
} 
From Lemma 1 we see that $p_{1}^{*}>v_{1}$ and $p_{2}^{*}>v_{2}$; hence, consumers are willing to pay a premium, in the form of a higher price on the item that is not on sale, to avoid the disappointment of leaving the store empty-handed. Notice also that $p_{1}^{*}$ and $p_{2}^{*}$ are increasing in the degree of availability of the bargain item, implying that the attachment effect carries over to the case of multiple goods evaluated along the same hedonic dimension. Moreover, it is easy to see that $p_{1}^{*}$ (resp. $p_{2}^{*}$ ) is increasing in $v_{2}$ (resp. $\left.v_{1}\right)$. Thus, expectations-based loss aversion creates a positive demand spillover across products, despite these being substitutes. Indeed, both $p_{1}^{*}$ and $p_{2}^{*}$ are written as the sum of two parts: the product's intrinsic value and the spillover effect due to loss aversion.

Although it is optimal for the seller to provide the bargain only in limited availability, she has to supply enough of it to exploit consumers' attachment. Indeed, when choosing the optimal supply (or availability) of the bargain item, the seller needs to take into account two effects. On the one hand, a high availability of the bargain makes consumers more attached to the idea of buying and this allows the seller to charge a higher price for the rip-off. On the other hand, a greater availability of the bargain necessarily means fewer sales of the rip-off. When choosing the supply level of the bargain, the seller optimally trades off these two effects. Moreover, she always supplies more units of the rip-off. ${ }^{25}$

Finally, the choice of which product to put on sale depends on the degree of substitutability between the products as well as on the difference in their marginal costs. The following lemma characterizes the seller's choice of the bargain item.

Lemma 2 If $v_{1}=v_{2}$ the seller uses as the bargain the item with the higher marginal cost. For $v_{1}>v_{2}$, there are three different cases: (i) if $v_{1}-v_{2}>0>c_{1}-c_{2}$, the seller uses item 2 as the bargain; (ii) if $v_{1}-v_{2}=c_{1}-c_{2}$, the seller uses item 1 as the bargain; and (iii) if $v_{1}-v_{2}>c_{1}-c_{2}>0$ there exists a $\widehat{\delta}>0$ such that the seller uses item 2 as the bargain if $v_{1}-v_{2}-\left(c_{1}-c_{2}\right)>\widehat{\delta}$ and item 1 otherwise.

It is worth emphasizing that, quite interestingly, the seller might offer a deal on item 1 even if $v_{1}>v_{2}$ and $v_{1}-c_{1}>v_{2}-c_{2}$. Although it might seem counterintuitive, there are two different effects that can induce the seller to put the superior product on sale. First, as $v_{1}+p_{1}^{\min }>v_{2}+p_{2}^{\min }$ consumers' expected gain-loss disutility when planning to buy only the bargain item is larger when the bargain is the superior good; that is, consumers face greater uncertainty in their consumption outcomes when planning to buy only the bargain if the superior product is put on sale. This in turn implies that if the superior item is offered for a low price, consumers are willing to pay an even higher premium to avoid the disappointment over not getting the deal. Hence, if the difference $v_{1}-v_{2}$ is relatively small, the seller prefers to use item 1 as the bargain even if $c_{1}=c_{2}$. Second, if $c_{2}<c_{1}$, by using item 1 as the bargain, the seller reduces her total cost by more compared to the case in which item 2 is the bargain. Figure 1 shows how the profitability of different schemes changes with $v_{1}$ if the difference in marginal costs is small. The black line represents the seller's profits when supplying only item 1 at price $p_{1}=v_{1}$, whereas the green and red curves depict the seller's profits with a limited-availability strategy when either item 1 or 2 is used as the bargain item, respectively. ${ }^{26}$ Concerning the choice of the bargain, we can distinguish three different regions, delimited by the two dashed vertical lines. For relatively low values of $v_{1}$, the profit-maximizing strategy is to offer a limited-availability deal on item 1 . As $v_{1}$

\footnotetext{
${ }^{25}$ See Lemma 4 in Appendix A

${ }^{26}$ Notice that the seller's overall profit is given by the upper envelope of these three curves.
} 


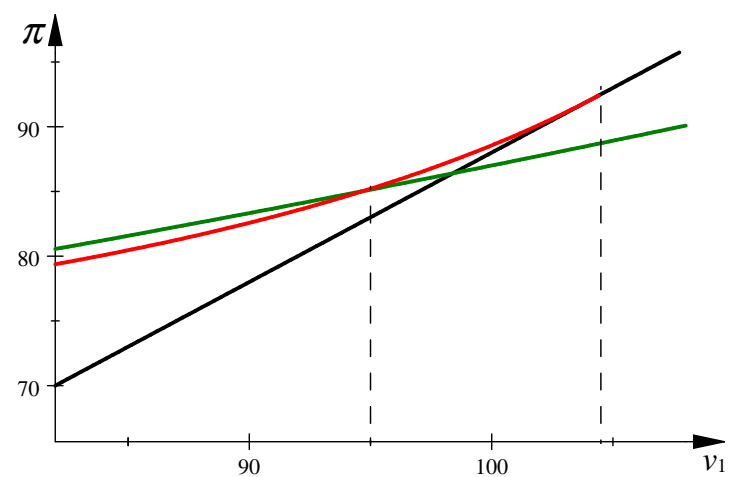

Figure 1: Profits as a function of $v_{1}$ for $\eta=1$, $\lambda=3, v_{2}=80, c_{1}=12, c_{2}=10$.

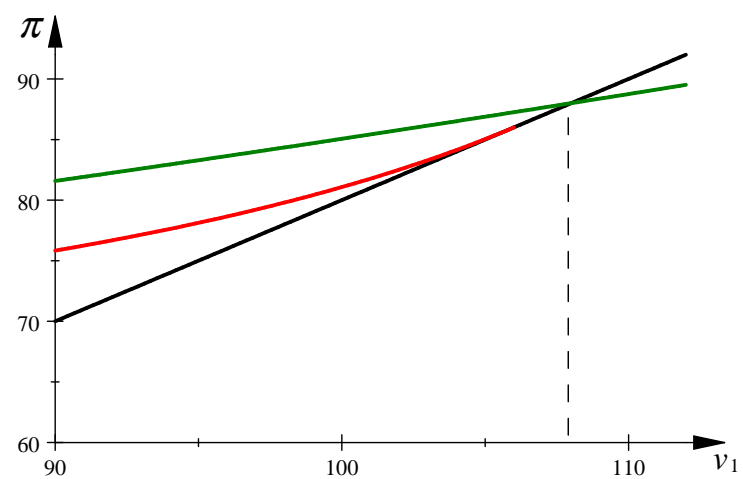

Figure 2: Profits as a function of $v_{1}$ for $\eta=1$, $\lambda=3, v_{2}=80, c_{1}=20, c_{2}=10$.

increases, the difference between the green and the red curve becomes smaller and eventually the two cross. Then, for intermediate values of $v_{1}$, the seller maximizes profits by using item 2 as the bargain. Finally, for high values of $v_{1}$ the seller prefers to supply only item 1 . When the difference in marginal costs is large, however, the seller only uses item 1 as the bargain. This is shown in Figure 2 where the green curve is always above the red one. In this case item 1 is more valuable to the consumer and has a larger social surplus; yet it is always offered on sale with limited availability. The following proposition characterizes the seller's profit-maximizing strategy.

Proposition 1 Fix any $\eta>0$ and $\lambda>1$. There exist two thresholds $\beta$ and $\gamma$ such that the seller's profit-maximizing strategy is as follows: (i) for $v_{1} \leq \beta$ she uses a limited-availability strategy with item 1 as the bargain and item 2 as the rip-off; (ii) for $v_{2} \geq \gamma$ she uses a limited-availability strategy with item 2 as the bargain and item 1 as the rip-off; and (iii) she supplies only item 1 with $p_{1}=v_{1}$ otherwise. Furthermore, the seller induces consumers to always buy and she attains a profit strictly greater than $v_{1}-c_{1}$ if both items are supplied.

Proposition 1 shows that in some cases it is optimal for the seller to offer a discount on one good, the bargain, which is however available only in limited supply and, at the same time, to charge a high price on the other substitute good, the rip-off. Notice that a limited-availability strategy is not always optimal. Intuitively, if the difference $v_{1}-v_{2}$ is very large, with a limited-availability strategy consumers face a lot of uncertainty in their consumption outcomes and this lowers their willingness to pay so that the seller prefers to supply only item 1. Yet, limited availability is optimal if consumers value the two products similarly and in this case the seller achieves a profit higher than $v_{1}-c_{1}$.

Interestingly, the bargain item can be a loss leader, i.e. $p_{i}^{\min }<c_{i}$. With classical preferences, loss leaders can be profitable only if the goods are complements. In my model, instead, loss leaders can be profitable even if the products are substitutes. The reason is that the loss-leading product is in short supply and in equilibrium some consumers will buy a different, more expensive product instead. Moreover, with limited availability the seller can attain strictly positive profits even when her products 
are socially wasteful, i.e. $v_{i}<c_{i}{ }^{27}$ This is possible because with limited availability and loss aversion, consumers' willingness to pay may exceed a product's intrinsic value.

Despite consumers being identical, in equilibrium limited availability separates them into two groups. Some consumers end up purchasing the good that is offered at a discount, making a bargain indeed. Others, instead, end up purchasing a similar good at a much higher price. The next result shows that in expectation consumers are hurt by this strategy.

Proposition 2 For any $\eta>0$ and $\lambda>1$ a consumer's expected surplus is at most zero and therefore he would be better off if he could commit to a strategy of never buying rather than following through his actual equilibrium strategy of always buying.

Proposition 2 suggests that limited-availability bargain sales are "manipulative" in the sense that they lead consumers to go shopping even though ex-ante they would prefer not to. Consumers enter the store expecting to make a bargain by purchasing a good on sale but might end up buying something else at an even higher price. Notice that the assumption about the seller being able to credibly commit in advance to the degree of availability is crucial. In fact, she has a strong incentive to always claim, ex-post, that the bargain item is sold-out and try to sell only the rip-off. Having rational expectations, however, consumers would correctly anticipate this and never plan to buy to begin with. Hence, the current FTC Guides Against Bait Advertising, by allowing to advertise limited-availability deals, provide the stores exactly with the commitment power they need to implement this exploitative scheme. Abolishing the role of limited-supply claims as a disclaimer for bait-and-switch or mandating retailers to issue rainchecks when advertised products are out of stock, would therefore improve consumers' welfare. In contrast, regulation in the EU gives retailers a much harder time with limited-availability bargain sales; in Germany, for example, current regulation outlaws advertising of goods which are held without appropriate quantities, with the latter being explicitly defined as "a coverage of demand for two days" under normal circumstances (see Strausz, 2007).

In addition to the consumers being worse off, the monopolist's product line is inefficient as, except for the non-generic case where the two goods have the same social surplus $\left(v_{1}-c_{1}=v_{2}-c_{2}\right)$, with a limitedavailability strategy the seller is purposely introducing a socially inferior substitute. Moreover, limited availability also affects the seller's incentives to invest in product development. To see this, suppose the seller can invest in either increasing a product's value from $v$ to $v+\varsigma$ with $\varsigma>0$ (value-increasing innovation) or in reducing the product's marginal cost by the same amount $\varsigma>0$ (cost-reducing innovation). If consumers have classical reference-free preferences, these two product improvements would have the same effect on the seller's profit. Proposition 3 shows that this is no longer the case when consumers are loss-averse.

Proposition 3 Fix any $\eta>0$ and $\lambda>1$. For the bargain item, the seller prefers to undertake a valueincreasing innovation. For the rip-off item, the seller prefers to undertake a cost-reducing innovation. Social welfare is higher under cost-reducing innovations than value-increasing ones. Consumers are hurt by value-increasing innovations and not affected by cost-reducing ones.

\footnotetext{
${ }^{27} \mathrm{~A}$ similar implication arises also in the single-product model of Heidhues and Köszegi (2014).
} 
The seller prefers to make the bargain item more appealing rather than reducing its cost. The intuition is that, as previously highlighted, expectations-based loss aversion creates a positive demand spillover between products and the more valuable the bargain is, the higher the price the seller can charge for the rip-off. On the other hand, because the rip-off is the item the seller supplies in larger quantities, she has a bigger incentive to invest in reducing its cost rather than increasing its value for consumers. From a social welfare perspective, cost-reducing innovations are better than value-increasing ones. The reason is that both types of innovation raise a product's social value from $v-c$ to $v-c+\varsigma$. Yet, as the seller supplies more units of the rip-off and she prefers cost-reducing innovations for this item, total welfare is higher in this case. With respect to (ex-ante) consumer welfare, instead, value-increasing innovations are always detrimental. This is because when the bargain item becomes more valuable, the seller increases the bargain's price and as well as the rip-off's price. Hence, consumers' average expenditure increases by a greater amount than consumers' average consumption utility. Cost-reducing innovations do not affect consumer welfare as neither price is affected by changes in costs. ${ }^{28}$

Identical Products and Relation with Heidhues and Köszegi (2014). I now argue that if the two products are identical my model is equivalent to a special case of Heidhues and Koszegi (2014)'s model. Let $v_{1}=v_{2}=v$ and $c_{1}=c_{2}=c$. The following result is a special case of Proposition 1 .

Corollary 1 Fix any $\eta>0$ and $\lambda>1$. The seller maximizes profits by offering $q^{*} \in\left(0, \frac{1}{2}\right)$ units of one good at price $p^{\min }=\frac{1+\eta}{1+\eta \lambda} v$ and $1-q^{*}$ units of the other good at price $p^{*}=v+\frac{2 q^{*} \eta(\lambda-1) p_{\min }}{1+\eta(\lambda-1) q^{*}}$. With this strategy the seller induces consumers to always buy and attains a profit strictly greater than $v-c$.

First, notice that with identical products the seller's optimal strategy is always a limited-availability one. Moreover, Corollary 1 can be seen as a reinterpretation of Heidhues and Köszegi (2014)'s result about the optimality of random sales: instead of using a stochastic pricing strategy for a single item, the seller can put one item on sale at a bargain price but in limited supply and at the same time raise the price of its substitutes. Indeed, the bargain price in my model coincides with the lowest price that the seller can charge in their model. Compared to this simple benchmark, Heidhues and Köszegi (2014)'s model entails greater price uncertainty for the consumers as it allows the seller to use more than two prices; my general model instead allows for both price and consumption uncertainty as the seller can supply two different products. Notice, however, that my general model makes clear predictions about the price and availability of the products whereas Heidhues and Köszegi (2014) could not fully characterize neither the probability of the seller holding a sale nor her non-sale prices.

\section{Extensions}

In this section, I analyze three extensions and discuss a number of further predictions of the model. ${ }^{29}$

Endogenous Product Line. In the baseline model, the seller is exogenously endowed with two different products that the consumers regard as imperfect substitutes. Yet, retailers can often create

\footnotetext{
${ }^{28}$ There is one caveat. Recall that when the difference $v_{1}-v_{2}$ becomes large, the seller maximizes profits by supplying only item 1 and making it fully available. Hence, if item 1 is the bargain, a value-increasing innovation is better than a cost-reducing one if after the innovation the seller prefers to supply only item 1.

${ }^{29}$ Proofs of the results in this section are relegated to the online appendix which also contains further technical analysis.
} 
almost-perfect substitutes of a given product through a small cosmetic change that does not affect consumers' valuations. For example, two TVs might have the same technology, screen size and number of pixels, thus providing consumers with the same picture quality, and just differ in their frame's color. To formally model this idea, consider a situation in which a seller can create a perfect substitute for a product at no additional cost and suppose she is allowed to price these de facto identical products differently. ${ }^{30}$ Therefore, the seller now has the choice between supplying two substitute (but distinct) products or just supplying two slightly different versions of the same product: the bargain version at a low price and the rip-off version at a high price. In either case, the seller can manipulate the availability of each item. The following proposition characterizes the seller's profit-maximizing strategy.

Proposition 4 For any $\eta>0$ and $\lambda>1$, the seller's profit-maximizing scheme always entails limited availability. If $v_{1}-c_{1}>v_{2}-c_{2}$, the seller maximizes profits by supplying two slightly different versions of item 1. If $v_{1}-c_{1} \leq v_{2}-c_{2}$, there exists a $\widetilde{v}_{2}$ such that: (i) for $v_{2} \leq \widetilde{v}_{2}$ the seller maximizes profits by using item 1 as the bargain and item 2 as the rip-off; (ii) for $v_{2}>\widetilde{v}_{2}$ the seller maximizes profits by supplying two slightly different versions of item 2.

Proposition 4 delivers several interesting results. First, if the seller can create a slightly different version of the same product, the profit-maximizing strategy is always a limited-availability one. This result can be interpreted as a foundation for the analysis in Heidhues and Köszegi (2014): although it might not be possible for a seller to credibly commit to an entire price distribution, she can achieve the same goal by introducing many slightly different - but equivalent from the consumers' point of view - versions of the same product. Moreover, if the socially superior product is the one consumers like best, the seller prefers to create a perfect substitute of this product instead of introducing another, inferior, one. However, if the socially superior item is the one consumers like the least, the seller might want to supply both products. The intuition is that, albeit socially inferior, item 1 is highly valuable to the consumers and this makes it an ideal candidate for a bait. Thus, in order to entice consumers, a seller might offer a product of inefficiently high quality at a bargain price.

Heterogeneous Tastes. I now consider a more general and realistic environment where consumers' valuations are heterogeneous. For simplicity, let $v_{1}=v_{2}=v$ and $c_{1}=c_{2}=c$ and suppose there is a unit mass of consumers who differ in their intrinsic value, $v$. From the seller's point of view $v$ is a random variable with distribution $F$. Let $F$ be strictly increasing, weakly convex and differentiable, with positive density $f$ everywhere on the support $\left[v^{l}, v^{h}\right]$ with $v^{h}>c \geq v^{l} \geq 0$. Without loss aversion the seller maximizes profits by choosing the price $\widehat{p}$ such that $\widehat{p}-c=\frac{1-F(\widehat{p})}{f(\widehat{p})}$. The consumer with value $v=\widehat{p}$ is the "marginal" type; that is, the type who is indifferent between buying or not.

If consumers are expectations-based loss-averse, however, the seller attains higher profits through the introduction of a limited-availability deal. With limited availability, a type- $v$ consumer will plan to buy with positive probability only if the price of the bargain does not exceed $p^{\min }(v)=\frac{1+\eta}{1+\eta \lambda} v$. Furthermore, from Section 4 we know that the optimal price for the rip-off is $p^{*}(v)=v+\frac{2 \eta(\lambda-1) q^{*} p^{\min }(v)}{1+\eta(\lambda-1) q^{*}}$. Let $\widehat{v}$ denote the marginal type with limited availability. The following proposition characterizes the seller's profit-maximizing strategy.

\footnotetext{
${ }^{30}$ An alternative interpretation is that the seller is able to charge different prices for different units of the same product. This happens, for example, when a retailer offers a discount only for the first units sold on a given day.
} 
Proposition 5 For any $\eta>0$ and $\lambda>1$, the seller's profit-maximizing scheme always entails limited availability. The bargain is priced at $p^{\min }(\widehat{v})$ and the rip-off is priced at $p^{*}(\widehat{v})$. Furthermore, $\widehat{v}<\widehat{p}$ and there exists a cutoff $v^{s}$ such that types in $\left[\widehat{v}, v^{s}\right)$ get negative expected utility in equilibrium.

The intuition for this result is that although the seller must now choose between serving a large share of the demand with a low price or a small share of the demand with a high price, with a limitedavailability strategy she can extract from the marginal consumer more than his intrinsic value for the product. Notice also that now the overall welfare effect of limited availability is ambiguous because with a limited-availability scheme the seller is serving a larger measure of consumers compared to the case of perfect availability as $\widehat{v}<\widehat{p}$. Nevertheless, some consumers, who would get a utility level of zero with perfect availability, are unambiguously worse off with this strategy.

Next, consider a case with both horizontally and vertically differentiated tastes. Suppose half of the consumers have valuations $\left(v_{1}, v_{2}\right)=\left(v_{H}, v_{L}\right)$, with $v_{H}>v_{L}>0$; the remaining half have valuations $\left(v_{1}, v_{2}\right)=\left(v_{L}, v_{H}\right)$. That is, half of the consumers prefer good 1 over good 2 and vice versa for the other half. Let $c_{1}=c_{2}=0$. With full availability, the seller would just set $p_{1}=p_{2}=v_{H}$ for a profit of $v_{H}$. With limited availability, instead, the seller offers a bargain on one of the goods by pricing it at $\frac{1+\eta}{1+\eta \lambda} v_{L}$ whereas the price of the rip-off is higher than $v_{H} .{ }^{31}$ The next proposition identifies a necessary and sufficient condition for a limited-availability strategy to be profit-maximizing.

Proposition 6 For any $\eta>0$ and $\lambda>1$ there exists a positive cutoff such that the seller's profitmaximizing strategy is a limited-availability one if and only if $\frac{v_{L}}{v_{H}}$ exceeds the cutoff.

Hence, if consumers value the items quite similarly, limited availability yields higher profits than perfect availability. However, whereas with perfect availability each consumer always gets his most preferred good, with limited availability some consumers will end up with the good they like the least.

Optimistic Consumers. So far I have closely followed the model of Köszegi and Rabin (2006) by assuming that consumers form rational beliefs. Suppose instead that when the seller announces a degree of availability $q$ for a bargain, consumers are overly optimistic and think they will get the bargain with probability $\widetilde{q}=\min \{\chi q, 1\}$, where $\chi>1$ parametrizes the degree of consumers' optimism. The seller knows $\chi$, but cannot be held liable for the difference between perceived and actual availability; however, she cannot reduce product availability below the level $q$ that she announces. Consumers still select a PPE purchasing plan, but they base their decisions and payoffs' comparison on the biased beliefs $\widetilde{q}{ }^{32}$ Then, for moderate levels of consumers' optimism, the seller chooses the highest price for the bargain that makes $\{\varnothing\}$ not a credible plan and a price for the rip-off such that consumers ex-ante are (perceive to be) indifferent between planning to buy only the bargain and always buying. Hence, except for the fact that consumers believe to be more likely to make a deal than they actually are, the seller's profit-maximizing strategy is qualitatively similar to the one derived in Section 4. Things are different, however, when consumers are highly optimistic. If consumers believe that they will find the cheaper item available for sure, the seller does not even need to offer a tempting deal to make $\{\varnothing\}$ not credible; instead, she can simply price it at its intrinsic value and pick for the other item the highest price at which consumers are willing to buy ex-post.

\footnotetext{
${ }^{31}$ See Section B.2 of the online appendix for further details.

${ }^{32}$ Section B.3 of the online appendix contains technical details and a formal statement of the results.
} 


\section{Conclusion}

Limited-availability sales are common among retailers selling durable consumer goods such as electronics, household appliances, or clothes. However, while this type of sales are familiar to consumers, economists have not devoted much attention to the importance of product availability in retailing. In this paper, I have provided an explanation, based on consumer loss aversion, for why a monopolist selling substitute goods might find it profitable to use limited-availability sales. The optimal strategy for the monopolist resembles bait-and-switch: she lures the consumers with a limited-availability deal on one good and cashes in with a high price on another one. The model predicts that more valuable or popular items are more likely to be used as baits and that the bait can be a loss leader.

I conclude the paper by discussing some of the model's limitations, as well as possible directions for future research. An important assumption is that, from the consumers' perspective, the two products belong to the same hedonic dimension. This creates an insurance effect: by planning to always buy a consumer can reduce the uncertainty in his consumption compared to the plan of buying only the bargain item. The monopolist then, is able to exploit this insurance effect by charging a high price for the rip-off item. If the two goods are evaluated along different hedonic dimensions, the insurance effect becomes weaker and the conditions for always buying to be the PPE become more restrictive. I have also assumed that all consumers show up at the store at the same time and are served randomly. During popular sales like Black Friday, however, consumers often wait in line outside stores before they open. Finally, it might be interesting to investigate which results of the model hold in a (possibly

imperfect) competitive environment. Indeed, a striking feature of popular sales like Black Friday is the concurrent use of limited-availability deals by competing retailers. 


\section{A Proofs}

I begin by proving the following, preliminary result.

Lemma 3 The market is fully covered: $q_{1}+q_{2}=1$.

Proof of Lemma 3: Let $q_{1}>0$ and $q_{2}>0$ with $q_{1}+q_{2}<1$. The seller wants to induce the consumers to always buy by selecting plan $\{1,2\}$ (resp. $\{2,1\}$ ) over $\{1, \varnothing\}$ (resp. $\{2, \varnothing\}$ ) For $p_{2} \geq p_{1}$, the highest price she can charge for item 2 is the one that makes the following inequality bind:

$$
E U[\{1,2\} \mid\{1,2\}] \geq E U[\{1, \varnothing\} \mid\{1, \varnothing\}]
$$

Substituting and re-arranging yields

$$
p_{2} \leq \frac{v_{2}\left[1+\eta(\lambda-1) q_{1}-\eta(\lambda-1)\left(1-q_{1}-q_{2}\right)\right]+2 \eta(\lambda-1) q_{1} p_{1}}{1+\eta(\lambda-1)\left(1-q_{2}\right)} .
$$

As the right-hand-side of the above inequality is increasing in $q_{2}$, the seller can raise $q_{2}$ up to $1-q_{1}$ and increase her profits without violating condition (3). A similar analysis applies if $p_{2}<p_{1}$.

Proof of Lemma 1: Let $q \in(0,1)$. We know that with limited availability $p_{i}=p_{i}^{\min }$ for one good; let this be good 2. I now show that it is not profitable for the seller to choose $p_{1}$ such that plan $\{2,1\}$ is the unique $\mathrm{PE}$ for the consumers.

First, under plan $\{2,1\}$, a consumer's reference point is to enjoy $v_{2}$ and pay $p_{2}^{\min }$ with probability $(1-q)$ and to enjoy $v_{1}$ and pay $p_{1}$ with probability $q$. Suppose that a consumer arrives at the store and finds only good 1 available at price $p_{1}>p_{2}^{\min }$. If he follows his plan and buys, his utility is:

$$
U\left[\left(v_{1}, p_{1}\right) \mid\{2,1\}\right]=v_{1}-p_{1}+\eta(1-q)\left(v_{1}-v_{2}\right)-\eta \lambda(1-q)\left(p_{1}-p_{2}^{\min }\right) .
$$

If instead he deviates from his original plan and does not buy, his utility is

$$
U[(0,0) \mid\{2,1\}]=-\eta \lambda q v_{1}-\eta \lambda(1-q) v_{2}+\eta q p_{1}+\eta(1-q) p_{2}^{\min } .
$$

Hence, the consumer will not deviate from his original plan when

$$
U\left[\left(v_{1}, p_{1}\right) \mid\{2,1\}\right] \geq U[(0,0) \mid\{2,1\}] .
$$

Substituting the explicit expression for $p_{2}^{\min }$ and rearranging yields

$$
p_{1} \leq \frac{[1+\eta(1-q)+\eta \lambda q] v_{1}+\eta(\lambda-1)(1-q) v_{2}\left(1+\frac{1+\eta}{1+\eta \lambda}\right)}{1+\eta q+\eta \lambda(1-q)} \equiv \bar{p}_{1}(q)
$$

So $\bar{p}_{1}(q)$ is the highest price of good 1 that makes $\{2,1\}$ a PE when $p_{2}=p_{2}^{\text {min }}$. We already know that $\{\varnothing\}$ is not a PE when $p_{2}=p_{2}^{\min }$ and it is easy to see that $\{1, \varnothing\}$ is not a PE either for $p_{1}>p_{2}^{\text {min }}$. So we only need to check the conditions for plan $\{2, \varnothing\}$ to be a PE. Under plan $\{2, \varnothing\}$, a consumer's reference point is to enjoy $v_{2}$ and pay $p_{2}^{\min }$ with probability $(1-q)$ and to consume and pay nothing with probability $q$. Suppose that a consumer arrives at the store and finds only good 1 available at price $p_{1}>p_{2}^{\min }$. If he follows his original plan and does not buy his utility is:

$$
U[(0,0) \mid\{2, \varnothing\}]=0-\eta \lambda(1-q)\left(v_{2}-0\right)+\eta(1-q)\left(p_{2}^{\min }-0\right) .
$$


If instead he deviates from his original plan and buys good 1 , his utility is

$$
\begin{aligned}
U\left[\left(v_{1}, p_{1}\right) \mid\{2, \varnothing\}\right]= & v_{1}-p_{1}+\eta q\left(v_{1}-0\right)+\eta(1-q)\left(v_{1}-v_{2}\right) \\
& -\eta \lambda q\left(p_{1}-0\right)-\eta \lambda(1-q)\left(p_{1}-p_{2}^{\min }\right) .
\end{aligned}
$$

Hence, the consumer will deviate from his original plan when

$$
U\left[\left(v_{1}, p_{1}\right) \mid\{2, \varnothing\}\right] \geq U[(0,0) \mid\{2, \varnothing\}]
$$

Substituting the explicit expression for $p_{2}^{\min }$ and rearranging yields

$$
p_{1} \leq \frac{(1+\eta) v_{1}+\eta(\lambda-1)(1-q) v_{2}\left(1+\frac{1+\eta}{1+\eta \lambda}\right)}{1+\eta \lambda} \equiv \widetilde{p}_{1}(q) \text {. }
$$

So $\widetilde{p}_{1}(q)$ is the highest price of good 1 that makes $\{2, \varnothing\}$ not a PE when $p_{2}=p_{2}^{\min }$. It is readily verified that $\bar{p}_{1}(q)>\widetilde{p}_{1}(q) \Leftrightarrow q>0$. Hence, for $p_{1} \leq \widetilde{p}_{1}(q)$ plan $\{2,1\}$ is the unique PE whereas, for $\bar{p}_{1}(q) \geq p_{1}>\widetilde{p}_{1}(q)$ both $\{2,1\}$ and $\{2, \varnothing\}$ are personal equilibria; but $\{2,1\}$ is the PPE if and only if

$$
E U[\{2,1\} \mid\{2,1\}] \geq E U[\{2, \varnothing\} \mid\{2, \varnothing\}] .
$$

Substituting and rearranging yields

$$
p_{1} \leq v_{1}+\frac{2(1-q) \eta(\lambda-1)\left[v_{2}(2+\eta+\eta \lambda)-v_{1}(1+\eta \lambda)\right]}{(1+\eta \lambda)[1+\eta(\lambda-1)(1-q)]} \equiv p_{1}^{*}(q)
$$

It is easy to see that $p_{1}^{*}(q)>\widetilde{p}_{1}(q)$. Next, we have that

$$
p_{1}^{*}(q)<\bar{p}_{1}(q) \Leftrightarrow \frac{v_{1}(1+\eta \lambda)}{\left[\frac{1-\eta(\lambda-1)(1-q)}{1+\eta(\lambda-1)(1-q)}-\frac{1+\eta(1-q)+\eta \lambda q}{1+\eta q+\eta \lambda(1-q)}\right]^{-1}}<\frac{v_{2}(2+\eta+\eta \lambda)}{\left[\frac{\eta(\lambda-1)(1-q)}{1+\eta q+\eta \lambda(1-q)}-\frac{2 \eta(\lambda-1)(1-q)}{1+\eta(\lambda-1)(1-q)}\right]^{-1}}
$$

The above condition holds as $v_{1}(1+\eta \lambda)<v_{2}(2+\eta+\eta \lambda)$ by assumption and

$$
\begin{gathered}
\frac{1-\eta(\lambda-1)(1-q)}{1+\eta(\lambda-1)(1-q)}-\frac{1+\eta(1-q)+\eta \lambda q}{1+\eta q+\eta \lambda(1-q)}<\frac{\eta(\lambda-1)(1-q)}{1+\eta q+\eta \lambda(1-q)}-\frac{2 \eta(\lambda-1)(1-q)}{1+\eta(\lambda-1)(1-q)} \\
\Leftrightarrow 1<\frac{1+\eta \lambda}{1+\eta \lambda+q \eta-q \lambda \eta}
\end{gathered}
$$

which is true for any $q \in(0,1)$ as $\lambda>1$. This proves that it is not profit-maximizing for the seller to make $\{2,1\}$ the unique $\mathrm{PE}$; instead, she can raise the price of the rip-off item up to a level where consumers are indifferent ex-ante between plans $\{2,1\}$ and $\{2, \varnothing\}$. The same argument applies to plan $\{1,2\}$ if the seller uses item 1 as the bargain (i.e., $p_{1}=p_{1}^{\min }$ ).

In the proof of Lemma 2 we use the following result:

Lemma 4 If the seller uses item 2 as the bargain, the optimal degree of availability of item 1 is $\bar{q}=\arg \max _{q} \pi\left(p_{1}^{*}, p_{2}^{\min }, q ; c_{1}, c_{2}\right)$. If instead she uses item 1 as the bargain, the optimal degree of availability of item 1 is $\underline{q}=\arg \max _{q} \pi\left(p_{1}^{\min }, p_{2}^{*}, q ; c_{1}, c_{2}\right)$. Furthermore, $\bar{q}>\frac{1}{2}, \bar{q} \geq 1-\underline{q}$ and, if $c_{1} \geq c_{2}$, $\underline{q}<\frac{1}{2}$. 
Proof of Lemma 4: Suppose the seller uses item 2 as the bargain and thus prices it at $p_{2}^{\min }$. Then, by Lemma 1 we know that the optimal price for item 1 is $p_{1}^{*}(q)$. This pair of prices provides the seller with profits equal to

$$
q\left[p_{1}^{*}(q)-c_{1}\right]+(1-q)\left(p_{2}^{\min }-c_{2}\right) .
$$

The above expression is maximized at

$$
\bar{q}=\frac{1+\eta(\lambda-1)}{\eta(\lambda-1)}-\frac{\sqrt{2}}{\eta(\lambda-1)} \sqrt{\frac{[1+\eta(\lambda-1)]\left[(2+\eta+\eta \lambda) v_{2}-(1+\eta \lambda) v_{1}\right]}{(1+\eta \lambda)\left(v_{2}+c_{2}-c_{1}-v_{1}\right)+(2+\eta+\eta \lambda) v_{2}}} .
$$

Notice that

$$
\bar{q} \geq \underbrace{\frac{1+\eta(\lambda-1)}{\eta(\lambda-1)}-\frac{\sqrt{2(1+\eta)(2+\eta \lambda+\eta)[1+\eta(\lambda-1)]}}{\eta(\lambda-1)(2+\eta \lambda+\eta)}}_{1-q^{*}}>\frac{1}{2}
$$

where the first inequality follows as

$$
\bar{q} \geq 1-q^{*} \Leftrightarrow(1+\eta \lambda)[1+\eta(\lambda-1)]\left[\left(c_{1}-c_{2}\right)(1+\eta)+\left(v_{2}-v_{1}\right)(1+\eta \lambda)\right] \leq 0
$$

which is true for any $\eta>0$ and $\lambda>1$ as $v_{1}-c_{1} \geq v_{2}-c_{2}$; and the second inequality follows as

$$
1-q^{*}>\frac{1}{2} \Leftrightarrow \quad \eta(\lambda-1)\left(\eta^{2} \lambda^{2}-\eta^{2}+6 \eta \lambda-6 \eta+4\right)>0
$$

which is true for any $\eta>0$ and $\lambda>1$. Next, consider the case in which the seller uses item 1 as the bargain. By Lemma 1 we know that the optimal price for item 2 is $p_{2}^{*}(q)$. This pair of prices provides the seller with profits equal to

$$
q\left(p_{1}^{\min }-c_{1}\right)+(1-q)\left[p_{2}^{*}(q)-c_{2}\right]
$$

The above expression is maximized at

$$
\underline{q}=\frac{\sqrt{2}}{\eta(\lambda-1)} \frac{\sqrt{v_{1}(1+\eta)[1+\eta(\lambda-1)]}}{\sqrt{\left(c_{1}-c_{2}+v_{2}\right)(1+\eta \lambda)+v_{1}(1+\eta)}}-\frac{1}{\eta(\lambda-1)} .
$$

Notice that

$$
\underline{q}<\frac{1}{2} \Leftrightarrow v_{1}(\eta+1)\left[4 \eta(\lambda-1)+4-\eta^{2}(\lambda-1)^{2}\right]<[\eta(\lambda-1)+2]^{2}\left(c_{1}-c_{2}+v_{2}\right)(1+\eta \lambda) .
$$

The inequality is satisfied for $c_{1} \geq c_{2}$ as $4 \eta(\lambda-1)+4-\eta^{2}(\lambda-1)^{2}<[\eta(\lambda-1)+2]^{2}$ and, by Assumption 2, $v_{1}(\eta+1)<v_{2}(1+\eta \lambda)$. Finally, we have that

$$
\begin{gathered}
\bar{q} \geq 1-\underline{q} \\
\Leftrightarrow \quad \frac{v_{2}(2+\eta+\eta \lambda)-v_{1}(1+\eta \lambda)}{\left(-c_{1}+c_{2}-v_{1}\right)(1+\eta \lambda)+v_{2}(3+\eta+2 \eta \lambda)} \leq \frac{v_{1}(1+\eta)}{\left(c_{1}-c_{2}+v_{2}\right)(1+\eta \lambda)+v_{1}(1+\eta)} \\
\Leftrightarrow \quad v_{2}(2+\eta \lambda+\eta)\left(v_{2}-v_{1}+c_{1}-c_{2}\right)-\eta(\lambda-1) v_{1}\left(c_{1}-c_{2}\right) \leq 0
\end{gathered}
$$

which follows by Assumption 1 and 2 . 
Proof of Lemma 2: Let $\pi_{1} \equiv \pi\left(p_{1}^{*}, p_{2}^{\min }, \bar{q} ; c_{1}, c_{2}\right)$ and $\pi_{2} \equiv \pi\left(p_{1}^{\min }, p_{2}^{*}, \underline{q} ; c_{1}, c_{2}\right)$ and recall that $\bar{q}=\arg \max _{q} \pi\left(p_{1}^{*}, p_{2}^{\min }, q ; c_{1}, c_{2}\right)$ and $\underline{q}=\arg \max _{q} \pi\left(p_{1}^{\min }, p_{2}^{*}, q ; c_{1}, c_{2}\right)$. First, suppose that $v_{1}=v_{2}$ and $c_{1}=c_{2}$. In this case $p_{1}^{\min }=p_{2}^{\min }, p_{1}^{*}=p_{2}^{*}$ and $\bar{q}=1-\underline{q}$ so that $\pi_{1}=\pi_{2}$. Therefore the seller is indifferent between which item to use as the bargain. Furthermore, it is easy to see that if $v_{1}=v_{2}$ but $c_{1} \neq c_{2}$, the seller maximizes profits by using as the bargain the one with the higher marginal cost.

Next, suppose to raise $v_{1}$ and $c_{1}$ by the same amount $\delta_{v}=\delta_{c}>0$ so that $v_{1}>v_{2}$ but $v_{1}-v_{2}=c_{1}-c_{2}$. The effect of these changes on profits are

$$
d \pi_{1} \approx \frac{\partial \pi_{1}}{\partial v_{1}} \delta_{v}+\frac{\partial \pi_{1}}{\partial c_{1}} \delta_{c}=\left(\bar{q} \frac{\partial p_{1}^{*}}{\partial v_{1}}-\bar{q}\right) \delta_{v}
$$

and

$$
d \pi_{2} \approx \frac{\partial \pi_{2}}{\partial v_{1}} \delta_{v}+\frac{\partial \pi_{2}}{\partial c_{1}} \delta_{c}=\left[\underline{q} \frac{1+\eta}{1+\eta \lambda}+(1-\underline{q}) \frac{\partial p_{2}^{*}}{\partial v_{1}}-\underline{q}\right] \delta_{v}
$$

Substituting and re-arranging, it follows that $d \pi_{2}>d \pi_{1}$ if and only if

$$
\frac{\eta(\lambda-1) \underline{q}}{1+\eta \lambda}\left[\frac{2(1-\underline{q})(1+\eta)-\underline{q} \eta(\lambda-1)-1}{\underline{q} \eta(\lambda-1)+1}\right]>\bar{q}\left[\frac{1-\eta(\lambda-1)(1-\bar{q})}{1+\eta(\lambda-1)(1-\bar{q})}-1\right] \text {. }
$$

As the expression on the right-hand-side of (4) is negative, it suffices to show that

$$
2(1-\underline{q})(1+\eta)-\underline{q} \eta(\lambda-1)-1>0 \Leftrightarrow \frac{1+2 \eta}{2+\eta+\eta \lambda}>\underline{q} .
$$

Substituting and re-arranging yields

$$
\frac{2+\eta+\eta \lambda+\eta(\lambda-1)(1+2 \eta)}{2+\eta+\eta \lambda}>\sqrt{\frac{2+\eta+\eta \lambda+\eta(\lambda-1)(1+2 \eta)}{2+\eta+\eta \lambda}}
$$

which holds for any $\eta>0$ and $\lambda>1$. Thus, the seller always uses item 1 as the bargain if $v_{1}>v_{2}$ but $v_{1}-v_{2}=c_{1}-c_{2}$.

Finally, suppose either $\delta_{v} \geq 0>\delta_{c}$ or $\delta_{v}>\delta_{c}>0$ so that $v_{1} \geq v_{2}$ and $v_{1}-c_{1}>v_{2}-c_{2}$. The effect of these changes on profits are

$$
d \pi_{1} \approx \frac{\partial \pi_{1}}{\partial v_{1}} \delta_{v}+\frac{\partial \pi_{1}}{\partial c_{1}} \delta_{c}=\bar{q} \frac{\partial p_{1}^{*}}{\partial v_{1}} \delta_{v}-\bar{q} \delta_{c}
$$

and

$$
d \pi_{2} \approx \frac{\partial \pi_{2}}{\partial v_{1}} \delta_{v}+\frac{\partial \pi_{2}}{\partial c_{1}} \delta_{c}=\left[\underline{q} \frac{1+\eta}{1+\eta \lambda}+(1-\underline{q}) \frac{\partial p_{2}^{*}}{\partial v_{1}}\right] \delta_{v}-\underline{q} \delta_{c} .
$$

By substituting and re-arranging, it follows that $d \pi_{1} \geq d \pi_{2}$ if and only if

$$
\left[\frac{1-\eta(\lambda-1)(1-\bar{q})}{1+\eta(\lambda-1)(1-\bar{q})} \bar{q}-\frac{1+\eta}{1+\eta \lambda} \underline{q}-(1-\underline{q}) \frac{1+\eta}{1+\eta \lambda} \frac{2 \underline{q} \eta(\lambda-1)}{1+\underline{q} \eta(\lambda-1)}\right] \delta_{v} \geq(\bar{q}-\underline{q}) \delta_{c} .
$$

If $\delta_{v}=\delta_{c}>0$ condition (5) can't possibly hold as it would coincide with the opposite of condition (4); but if either $\delta_{v}>\delta_{c}>0$ or $\delta_{v} \geq 0>\delta_{c}$ it can hold. For example, it is readily satisfied for $\delta_{v}=0$ and $\delta_{c}<0$ so that the seller always uses item 2 as the bargain if $v_{1}=v_{2}$ but $v_{1}-v_{2}>c_{1}-c_{2}$. Let $\widehat{\delta}$ be the value of $\delta_{v}-\delta_{c}$ for which (5) binds; if such a value exists then it is unique because the term on 
the left-hand-side of (5) is continuous and increasing in $\delta_{v}$ whereas the term on the right-hand-side of (5) is continuous and increasing in $\delta_{c}$. This concludes the proof.

Proof of Proposition 1: For arbitrary prices $\left(p_{1}, p_{2}\right)$ and quantities $(q, 1-q)$ the monopolist's profit is

$$
\pi\left(p_{1}, p_{2}, q ; c_{1}, c_{2}\right)=q\left(p_{1}-c_{1}\right)+(1-q)\left(p_{2}-c_{2}\right) .
$$

The seller has three options:

i) Set $p_{2}=p_{2}^{\min }, p_{1}=p_{1}^{*}(q)$ and $q=\bar{q}$. In this case the seller's profit is

$$
\pi_{1} \equiv \bar{q}\left[p_{1}^{*}(\bar{q})-c_{1}\right]+(1-\bar{q})\left(p_{2}^{\min }-c_{2}\right)
$$

ii) Set $p_{1}=p_{1}^{\min }, p_{2}=p_{2}^{*}(q)$ and $q=\underline{q}$. In this case the seller's profit is

$$
\pi_{2} \equiv \underline{q}\left(p_{1}^{\min }-c_{1}\right)+(1-\underline{q})\left[p_{2}^{*}(\underline{q})-c_{2}\right] .
$$

iii) Set $p_{i}=v_{i}$ for $i=1,2$. This pair of prices provides the seller with profits equal to

$$
q\left(v_{1}-c_{1}\right)+(1-q)\left(v_{2}-c_{2}\right)
$$

The above expression is maximized at $q=1$ as $v_{1}-c_{1} \geq v_{2}-c_{2}$.

Depending on the degree of substitutability between the two goods, their marginal costs and the degree of loss aversion, the seller will choose the option that will give her the highest profit. Suppose first that the seller uses item 1 as the bargain. Then,

$$
\begin{gathered}
\pi_{2} \geq v_{1}-c_{1} \\
\Leftrightarrow \quad v_{1} \leq\left(v_{2}-c_{2}+c_{1}\right)\left(\frac{1+\eta \lambda}{1+\eta}\right) \Xi(\eta, \lambda) \equiv \beta\left(v_{2}, c_{1}, c_{2}, \eta, \lambda\right) .
\end{gathered}
$$

where

$\Xi(\eta, \lambda) \equiv[1+\eta(\lambda-1)] \times\left[\frac{3 \eta+4 \eta^{2}+2 \eta^{3}+\eta^{2} \lambda^{2}(1+\eta)-\eta \lambda\left(1+3 \eta^{2}+4 \eta\right)-2 \eta(\lambda-1) \sqrt{2(1+\eta)^{3}}+1}{4 \eta\left(1+\eta^{3}\right)+\eta^{4} \lambda^{4}-2 \eta^{3} \lambda^{3}(1+3 \eta)+\eta^{2} \lambda^{2}\left(13 \eta^{2}+2 \eta-5\right)-2 \eta \lambda\left(6 \eta^{3}-3 \eta+1\right)+1}\right]$

Next, if the seller prefers to use item 2 as the bargain we have

$$
\pi_{1} \geq v_{1}-c_{1} \Leftrightarrow v_{2} \geq \frac{v_{1}-c_{1}+c_{2}+2 \eta(\lambda-1) v_{1}}{1+\eta(\lambda-1)\left(\frac{3+2 \eta \lambda+2 \eta}{1+\eta \lambda}\right)} \equiv \gamma\left(v_{1}, c_{1}, c_{2}, \eta, \lambda\right)
$$

To conclude the proof, notice that the seller's profit under perfect availability equals $v_{1}-c_{1}$. Because she would choose a different option only if this provides her with at least as much, it follows that her profits exceed $v_{1}-c_{1}$ if either option i) or ii) is profit-maximizing.

Proof of Proposition 2: Suppose the seller uses item 2 as the bargain. Then:

$$
\begin{aligned}
\bar{q}\left(p_{1}^{*}-c_{1}\right)+(1-\bar{q})\left(p_{2}^{\min }-c_{2}\right) & >v_{1}-c_{1} \\
& \geq \bar{q}\left(v_{1}-c_{1}\right)+(1-\bar{q})\left(v_{2}-c_{2}\right)
\end{aligned}
$$




$$
\Rightarrow \bar{q} p_{1}^{*}+(1-\bar{q}) p_{2}^{\min }>\bar{q} v_{1}+(1-\bar{q}) v_{2}
$$

In this case, therefore, a consumer expects to buy at an average price strictly greater than his average valuation. Hence, his consumption utility is negative. Furthermore, in any PE, expected gainloss utility is non-positive. If instead he could commit to plan $\{\varnothing\}$, both his consumption utility and his gain-loss utility would be zero. The same argument applies if item 1 is the bargain.

Proof of Proposition 3: First, consider the seller's profits when item 1 is the bargain:

$$
\pi_{2}=\underline{q}\left(p_{1}^{\min }-c_{1}\right)+(1-\underline{q})\left[p_{2}^{*}(\underline{q})-c_{2}\right] .
$$

Recall that the seller uses item 1 as the bargain if $v_{1} \leq \beta\left(v_{2}, c_{1}, c_{2}, \eta, \lambda\right)$. Applying the envelope theorem, we have:

$$
\begin{aligned}
\frac{d \pi_{2}}{d v_{1}} & =\underline{q} \frac{\partial p_{1}^{\min }}{\partial v_{1}}+(1-\underline{q}) \frac{p_{2}^{*}(\underline{q})}{\partial v_{1}} \\
& =\frac{1+\eta}{1+\eta \lambda} \underline{q}\left[1+\frac{2 \eta(\lambda-1)(1-\underline{q})}{1+\eta(\lambda-1) \underline{q}}\right] \\
& >\underline{q}=\left|\frac{d \pi_{2}}{d c_{1}}\right|
\end{aligned}
$$

where the inequality follows as

$$
\begin{aligned}
1+\frac{2 \eta(\lambda-1)(1-\underline{q})}{1+\eta(\lambda-1) \underline{q}} & >\frac{1+\eta \lambda}{1+\eta} \Leftrightarrow \frac{1+2 \eta}{2+\eta \lambda+\eta}>\underline{q} \\
& \Leftrightarrow \quad v_{1}<\underbrace{\frac{2(\eta+1)\left(\eta^{2} \lambda^{2}-\eta^{2} \lambda+2 \eta \lambda-\eta+1\right)}{2 \eta+3 \eta^{2}+2 \eta^{3}+\eta^{2} \lambda^{2}+2 \eta \lambda-2 \eta^{2} \lambda-2 \eta^{3} \lambda+2}}_{>1}\left(c_{1}-c_{2}+v_{2}\right)
\end{aligned}
$$

and tedious algebra shows that

$$
\frac{2(\eta+1)\left(\eta^{2} \lambda^{2}-\eta^{2} \lambda+2 \eta \lambda-\eta+1\right)\left(c_{1}-c_{2}+v_{2}\right)}{2 \eta+3 \eta^{2}+2 \eta^{3}+\eta^{2} \lambda^{2}+2 \eta \lambda-2 \eta^{2} \lambda-2 \eta^{3} \lambda+2}>\beta\left(v_{2}, c_{1}, c_{2}, \eta, \lambda\right) .
$$

Similarly, we have

$$
\frac{d \pi_{2}}{d v_{2}}=(1-\underline{q}) \underbrace{\frac{\partial p_{2}^{*}(\underline{q})}{\partial v_{2}}}_{=1}=\left|\frac{d \pi_{2}}{d c_{2}}\right|
$$

Next, consider the seller's profits when item 2 is used as the bargain:

$$
\pi_{1}=\bar{q}\left[p_{1}^{*}(\bar{q})-c_{1}\right]+(1-\bar{q})\left(p_{2}^{\min }-c_{2}\right)
$$

Then,

$$
\frac{d \pi_{1}}{d v_{1}}=\bar{q} \frac{\partial p_{1}^{*}(\bar{q})}{\partial v_{1}}=\bar{q} \underbrace{\left[\frac{1-\eta(\lambda-1)(1-\bar{q})}{1+\eta(\lambda-1)(1-\bar{q})}\right]}_{<1}<\bar{q}=\left|\frac{d \pi_{1}}{d c_{1}}\right|
$$


Similarly,

$$
\begin{aligned}
\frac{d \pi_{1}}{d v_{2}} & =\bar{q} \frac{\partial p_{1}^{*}(\bar{q})}{\partial v_{2}}+(1-\bar{q}) \frac{\partial p_{2}^{\min }}{\partial v_{2}} \\
& =(1-\bar{q})\left[\frac{2 \eta(\lambda-1)(2+\eta \lambda+\eta) \bar{q}}{(1+\eta \lambda)[1+\eta(\lambda-1)(1-\bar{q})]}+\frac{1+\eta}{1+\eta \lambda}\right] \\
& >(1-\bar{q})=\left|\frac{d \pi_{1}}{d c_{2}}\right|
\end{aligned}
$$

where the inequality follows as

$$
\frac{2 \eta(\lambda-1)(2+\eta \lambda+\eta) \bar{q}}{(1+\eta \lambda)[1+\eta(\lambda-1)(1-\bar{q})]}+\frac{1+\eta}{1+\eta \lambda}>1 \Leftrightarrow 2(2+\eta \lambda+\eta) \bar{q}>1+\eta(\lambda-1)(1-\bar{q}) \Leftarrow \bar{q}>\frac{1}{2} .
$$

Cost-reducing innovations are better than value-increasing ones from a social welfare perspective because the seller prefers to undertake cost-reducing innovations for the rip-off item and value-increasing innovations for the bargain item and from Lemma 4 and Lemma 2 we know that $\bar{q}>\frac{1}{2}>\underline{q}$; that is, the seller supplies more units of the rip-off item. Finally, let

$V_{1}=\bar{q}\left(v_{1}-p_{1}^{*}(\bar{q})\right)+(1-\bar{q})\left(v_{2}-p_{2}^{\min }\right)-\eta(\lambda-1) \bar{q}(1-\bar{q})\left(v_{1}-v_{2}\right)-\eta(\lambda-1) \bar{q}(1-\bar{q})\left(p_{1}^{*}(\bar{q})-p_{2}^{\min }\right)$

and

$V_{2}=\underline{q}\left(v_{1}-p_{1}^{\min }\right)+(1-\underline{q})\left(v_{2}-p_{2}^{*}(\underline{q})\right)-\eta(\lambda-1) \underline{q}(1-\underline{q})\left(v_{1}-v_{2}\right)-\eta(\lambda-1) \underline{q}(1-\underline{q})\left(p_{2}^{*}(\underline{q})-p_{1}^{\min }\right)$

be a consumer's equilibrium expected utility when item 2 (resp. 1) is the bargain. Applying the envelope theorem, we have

$$
\begin{aligned}
\frac{d V_{1}}{d v_{2}} & =-\bar{q} \frac{\partial p_{1}^{*}(\bar{q})}{\partial v_{2}}+(1-\bar{q})\left(1-\frac{1+\eta}{1+\eta \lambda}\right)+\eta(\lambda-1) \bar{q}(1-\bar{q})-\eta(\lambda-1) \bar{q}(1-\bar{q})\left(\frac{\partial p_{1}^{*}(\bar{q})}{\partial v_{2}}-\frac{1+\eta}{1+\eta \lambda}\right) \\
& =-(1-\bar{q}) \frac{\eta(\lambda-1)}{1+\eta \lambda}(2 \bar{q}+\bar{q} \eta+\bar{q} \lambda \eta-1) \\
& <0
\end{aligned}
$$

where the inequality follows as $\bar{q}>\frac{1}{2}$. Similarly, we have

$$
\begin{aligned}
\frac{d V_{2}}{d v_{1}} & =\underline{q}\left(1-\frac{1+\eta}{1+\eta \lambda}\right)-(1-\underline{q}) \frac{\partial p_{2}^{*}(\underline{q})}{\partial v_{1}}-\eta(\lambda-1) \bar{q}(1-\bar{q})-\eta(\lambda-1) \underline{q}(1-\underline{q})\left(\frac{\partial p_{2}^{*}(\underline{q})}{\partial v_{1}}-\frac{1+\eta}{1+\eta \lambda}\right) \\
& =-\underline{q} \frac{\eta(\lambda-1)}{1+\eta \lambda}(\eta-2 \underline{q}-\underline{q} \eta+\lambda \eta-\underline{q} \lambda \eta+1) \\
& <0
\end{aligned}
$$

where the inequality follows as $\underline{q}<\frac{1}{2}$.

\section{References}

Abeler, J., Falk, A. Goette, L. and Huffman, D. "Reference Points and Effort Provision." American Economic Review, Vol. 101(2011), pp. 470-492. 
Ambrus, A. And Weinstein, J. "Price Dispersion and Loss Leaders." Theoretical Economics, Vol. 3 (2008), pp. 525-537.

Anderson, E., Fitzsimons, G.J. and Simester, D. "Measuring and Mitigating the Cost of Stockouts." Management Science, Vol. 52 (2006), pp. 1751-1763.

Anupindi, R., Dada, M. And Gupta, S. "Estimation of Consumers Demand with Stock-Out Based Substitution: An Application to Vending Machine Products." Marketing Science, Vol. 17 (1998) pp. 406-423.

Bils, M. "Studying Price Markups from Stockout Behavior." Mimeo, 2004.

Carbajal, J.C. And Ely, J. "A Model of Price Discrimination under Loss Aversion and StateContingent Reference Points." Theoretical Economics, forthcoming.

Chevalier, J.A., Kashyap, A.K. And Rossi, P.E. "Why Don't Prices Rise During Periods of Peak Demand? Evidence from Scanner Data." American Economic Review, Vol. 93 (2003), pp. 15-37.

Conlon, C.T. And Mortimer, J.H. "Effects of Product Availability: Experimental Evidence." Mimeo, 2011

DANA, J.D. JR. "Equilibrium Price Dispersion under Demand Uncertainty: The Roles of Costly Capacity and Market Structure." Rand Journal of Economics, Vol. 30 (1999), pp. 632-660.

DANA, J.D. JR. "Monopoly Price Dispersion under Demand Uncertainty." International Economic Review, Vol. 42 (2001), pp. 649-670.

DeGraba, P. "Buying Frenzies and Seller-Induced Excess Demand." Rand Journal of Economics, Vol. 26 (1995), pp. 331-342.

Della Vigna, S. and Malmendier, U. "Contract Design and Self-Control: Theory and Evidence." Quarterly Journal of Economics, Vol. 119 (2004), pp. 353-402.

Deneckere, R. And Peck, J. "Competition over Price and Service Rate when Demand is Stochastic: A Strategic Analysis." Rand Journal of Economics, Vol. 26 (1995), pp. 148-162.

Diels, J.L., Wiebach, N. And Hildebrandt, L. "The impact of promotions on consumer choices and preferences in out-of-stock situations." Journal of Retailing and Consumer Services, Vol. 20 (2013), pp. 587-598.

Eliaz, K. And Spiegler, R. "Contracting with Diversely Naïve Agents." Review of Economic Studies, Vol. 73 (2006), pp. 689-714.

Eliaz, K. And Spiegler, R. "Consumer Optimism and Price Discrimination." Theoretical Economics, Vol. 3 (2008), pp. 459-497.

Eliaz, K. And Spiegler, R. "On the Strategic Use of Attention Grabbers." Theoretical Economics, Vol. 6 (2011), pp. 127-155.

Ellison, G. And Fisher Ellison, S. "Search, Obfuscation, and Price Elasticities on the Internet." Econometrica, Vol. 77 (2009), pp. 427-452.

Emmelhainz, M.A., Stock, J.R. And Emmelhainz , L.W. "Consumer Responses to Retail Stockouts." Journal of Retailing, Vol. 67 (1991), pp. 139-147.

Ericson Marzilli, K.M. And Fuster, A. "Expectations as Endowments: Evidence on ReferenceDependent Preferences from Exchange and Valuation Experiments." Quarterly Journal of Economics, Vol. 126 (2011), pp. 1879-1907.

Fitzsimons, G.J. "Consumer Response to Stockouts." Journal of Consumer Research, Vol. 27 (2000), pp. 249-266. 
Gabaix, X. And Laibson, D. "Shrouded Attributes, Consumer Myopia, and Information Suppression in Competitive Markets." Quarterly Journal of Economics, Vol. 121 (2006), pp. 505-540.

Gerstner, E. And Hess, J. "Can Bait and Switch Benefit Consumers?" Marketing Science, Vol. 9 (1990), pp. 114-124.

Gilbert, R. And Klemperer, P. "An Equilibrium Theory of Rationing." Rand Journal of Economics, Vol. 31 (2000), pp. 1-21.

Gill, D. And Prowse, V. "A Structural Analysis of Disappointment Aversion in a Real Effort Competition." American Economic Review, Vol. 102 (2012), pp. 469-503.

Gruen, T., Corsten, D. And BraradwaJ, S. Retail Out of Stocks: A Worldwide Examination of Causes, Rates and Consumer Responses. Washington, D.C.: Grocery Manufacturers of America, 2002.

Grubb, M. "Selling to Overconfident Consumers." American Economic Review, Vol. 99 (2009), pp. 1770-1807.

Hahn, J., Kim, J., Kim, S. And Lee, J. "Price Discrimination with Loss Averse Consumers." Mimeo, 2015 .

Heidhues, P. And Köszegi, B. "Competition and Price Variation when Consumers are Loss Averse." American Economic Review, Vol. 98 (2008), pp. 1245-1268.

Heidhues, P. And Köszegi, B. "Regular Prices and Sales." Theoretical Economics, Vol. 9 (2014), pp. 217-251.

Herweg, F. And Mierendorff, K. "Uncertain Demand, Consumer Loss Aversion, and Flat-Rate Tariffs." Journal of the European Economic Association, Vol. 11 (2013), pp. 399-432.

Herweg, F., Müller, D. And Weinschenk, P. "Binary Payment Schemes: Moral Hazard and Loss Aversion." American Economic Review, Vol. 100 (2010), pp. 2451-2477.

Hess, J. And Gerstner, E. "Loss Leader Pricing and Rain Check Policy." Marketing Science, Vol. 6 (1987), pp. 358-374.

Hosken, D. And Reiffen, D. "Patterns of Retail Price Variation." Rand Journal of Economics, Vol. 35 (2004a), pp. 128-146.

Hosken, D. And Reiffen, D. "How Retailers Determine which Products Should Go on Sale." Journal of Consumer Policy, Vol. 27 (2004b), pp. 141-177.

In, Y. And Wright, J. "Loss-leader Pricing and Upgrades." Economic Letters, Vol. 122 (2014), pp. $19-22$.

Jing, X. AND Lewis, M. "Stockouts in Online Retailing." Journal of Marketing Research, Vol. 48 (2011), pp. 342-354.

Kahneman, D. And Tversky, A. "Prospect Theory: An Analysis of Decision under Risk." Econometrica, Vol. 47 (1979), pp. 263-291.

Kahneman, D., Knetsch, J.L. And Thaler, R. "Experimental Tests of the Endowment Effect and the Coase Theorem." Journal of Political Economy, Vol. 98 (1990), pp. 1325-1348.

Kahneman, D., Knetsch, J.L. And Thaler, R. "Anomalies: The Endowment Effect, Loss Aversion, and Status Quo Bias." Journal of Economic Perspectives, Vol. 5 (1991), pp. 193-206.

KamenicA, E. "Contextual Inference in Markets: On the Informational Content of Product Lines." American Economic Review, Vol. 98 (2008), pp. 2127-2149.

KARLE, H. "Creating Attachment through Advertising: Loss Aversion and Pre-Purchase Information." Mimeo, 2014. 
Karle, H. And Peitz, M. "Competition under Consumer Loss Aversion." Rand Journal of Economics, Vol. 45 (2014), pp. 1-31.

Karle, H., Kirchsteiger, G. And Peitz, M. "Loss Aversion and Consumption Choice: Theory and Experimental Evidence." American Economic Journal: Microeconomics, Vol. 7 (2015), pp. 101-120.

Kim, M. And Lennon, S.J. "Consumer Response to Online Apparel Stockouts." Psychology and Marketing, Vol. 28 (2011), pp. 115-144.

Klemperer, P. And Padilla, A.J. "Do Firms' Product Lines Include too Many Varieties?" Rand Journal of Economics, Vol. 28 (1997), pp. 472-488.

Konishi, H. And SAndfort, M. "Expanding Demand through Price Advertisement." International Journal of Industrial Organization, Vol. 20 (2002), pp. 965-994.

Köszegi, B. And Rabin, M. "A Model of Reference-Dependent Preferences." Quarterly Journal of Economics, Vol. 121 (2006), pp. 1133-1165.

Köszegi, B. And Rabin, M. "Reference-Dependent Risk Attitudes." American Economic Review, Vol. 97 (2007), pp. 1047-1073.

Lal, R. And Matutes, C. "Retail Pricing and Advertising Strategies." Journal of Business, Vol. 67 (1994), pp. 345-370.

Lazear, E. "Bait and Switch." Journal of Political Economy, Vol. 103 (1995), pp. 813-830.

Nakamura, E. And Steinsson, J. "Five Facts about Prices: Reevaluation of Menu Cost Models." Quarterly Journal of Economics, Vol. 123 (2008), pp. 1415-1464.

Rhodes, A. "Multiproduct Retailing." Review of Economic Studies, Vol. 82 (2015), pp. 360-390.

Salop, S. And Stiglitz, J. "Bargains and Ripoffs: A Model of Monopolistically Competitive Price Dispersion." Review of Economic Studies, Vol. 44 (1977), pp. 493-510.

SpIEgleR, R. "Monopoly pricing when consumers are antagonized by unexpected price increases: a "cover version" of the Heidhues-Köszegi-Rabin model." Economic Theory, Vol. 51 (2012), pp. 695-711.

Strausz, R. "Regulating Availability with Demand Uncertainty." German Economic Review, Vol. 8 (2007), pp. 107-121.

TAYlor, J.C. And FAWCett, S.E. "Retail On-Shelf Performance of Advertised Items: An Assessment of Supply Chain Effectiveness at the Point of Purchase." Journal of Business Logistics, Vol. 22 (2001), pp. 73-89.

Tversky, A. And Kahneman, D. "Loss Aversion in Riskless Choice: A Reference-Dependent Model." Quarterly Journal of Economics, Vol. 106 (1991), pp. 1039-1061.

Thanassoulis, J. "Haggling over Substitutes." Journal of Economic Theory, Vol. 117 (2004), pp. 217-245.

VArian, H. "A Model of Sales." American Economic Review, Vol. 70 (1980), pp. 651-659.

Zhou, J. "Reference Dependence and Market Competition." Journal of Economics and Management Strategy, Vol. 20 (2011), pp. 1073-1097.

Zhou, J. "Multiproduct Search and the Joint Search Effect." American Economic Review, Vol. 104 (2014), pp. 2918-2939.

Zinn, W. And LiU, P.C. "Consumer Response to Retail Stockouts." Journal of Business Logistics, Vol. 22 (2001), pp. 49-71. 


\section{Web Appendix (not for publication)}

This appendix collects omitted proofs from the main text and further extensions of the main model. In Section B I present proofs and technical details pertaining to the results in Section 5 . Then, I discuss two further extensions of the baseline model of Section 4. Section $\mathrm{C}$ analyzes a case in which the seller can commit only to the price of the bargain, but not to the price of the rip-off. Section D explores the consequences of relaxing Assumption 2.

\section{B Omitted Proofs and Additional Results from Section 5}

\section{B.1 Endogenous Product Line}

Because now the seller can supply two different versions of the same product, let $p_{i, j}^{*}$ be the price of the rip-off item $i$, when item $j$ is the bargain, for $i, j=1,2$ (see Lemma 1 in the main text).

Proof of Proposition 4: First, we prove that if the seller can create artificial substitutes, limited availability always yields higher profits than perfect availability. Let $v_{1}-c_{1}>v_{2}-c_{2}$ so that the maximum level of profits the seller can achieve with perfect availability is $v_{1}-c_{1}$. If the seller can create perfect substitutes for item 1 , then her profits are equal to

$$
q^{c}\left(p_{1,1}^{*}-c_{1}\right)+\left(1-q^{c}\right)\left(p_{1}^{\min }-c_{1}\right)
$$

where $q^{c}=\frac{1+\eta(\lambda-1)}{\eta(\lambda-1)}-\frac{\sqrt{2(1+\eta)(2+\eta \lambda+\eta)[1+\eta(\lambda-1)]}}{\eta(\lambda-1)(2+\eta \lambda+\eta)}$. Then, it suffices to show that

$$
q^{c}\left[1+\frac{2(1-q) \eta(\lambda-1)}{1+(1-q) \eta(\lambda-1)} \frac{1+\eta}{1+\eta \lambda}\right]+\left(1-q^{c}\right) \frac{1+\eta}{1+\eta \lambda}>1 \Leftrightarrow q^{c}>\frac{1+\eta(\lambda-1)}{\eta+\lambda \eta+2} .
$$

Substituting for $q^{c}$ yields

$$
2 \eta(\lambda-1)(\lambda \eta-\eta+1)\left(2 \eta^{2}+3 \eta+1\right)>0
$$

which holds for any $\eta>0$ and $\lambda>1$. A similar argument applies if $v_{1}-c_{1} \leq v_{2}-c_{2}$.

Next, we prove the second part of the proposition. Define $\pi_{1,2} \equiv \pi\left(p_{1,2}^{*}, p_{2}^{\min }, \bar{q} ; c_{1}, c_{2}\right), \pi_{2,1} \equiv$ $\pi\left(p_{1}^{\min }, p_{2,1}^{*}, \underline{q} ; c_{1}, c_{2}\right), \pi_{1,1} \equiv \pi\left(p_{1,1}^{*}, p_{1}^{\min }, q^{c} ; c_{1}, c_{1}\right)$ and $\pi_{2,2} \equiv \pi\left(p_{2,2}^{*}, p_{2}^{\min }, q^{c} ; c_{2}, c_{2}\right)$, where $\bar{q}=$ $\arg \max _{q} \pi\left(p_{1,2}^{*}, p_{2}^{\min }, q ; c_{1}, c_{2}\right), \underline{q}=\arg \max _{q} \pi\left(p_{1}^{\min }, p_{2,1}^{*}, q ; c_{1}, c_{2}\right)$ and $q^{c}=\arg \max _{q} \pi\left(p_{i}^{\min }, p_{i, i}^{*}, q ; c_{i}, c_{i}\right)$, for $i \in\{1,2\}$. If $v_{1}=v_{2}$ and $c_{1}=c_{2}$, then $p_{1}^{\min }=p_{2}^{\min }, p_{1,2}^{*}=p_{1,1}^{*}=p_{2,2}^{*}=p_{2,1}^{*}$ and $\bar{q}=1-\underline{q}=q^{c}$ so that $\pi_{1,1}=\pi_{1,2}=\pi_{2,1}=\pi_{2,2}$.

Suppose to change $v_{1}$ by $d v_{1}$ and $c_{1}$ by $d c_{1}$ with either $d v_{1}>d c_{1} \geq 0$ or $d v_{1} \geq 0>d c_{1}$. By the envelope theorem the effect of these changes on profits are

$$
\begin{gathered}
d \pi_{1,2} \approx \frac{\partial \pi_{1,2}}{\partial v_{1}} d v_{1}+\frac{\partial \pi_{1,2}}{\partial c_{1}} d c_{1}=\bar{q} \frac{\partial p_{1,2}^{*}}{\partial v_{1}} d v_{1}-\bar{q} d c_{1} \\
d \pi_{2,1} \approx \frac{\partial \pi_{2,1}}{\partial v_{1}} d v_{1}+\frac{\partial \pi_{2,1}}{\partial c_{1}} d c_{1}=\left[\underline{q} \frac{1+\eta}{1+\eta \lambda}+(1-\underline{q}) \frac{\partial p_{2,1}^{*}}{\partial v_{1}}\right] d v_{1}-\underline{q} d c_{1} \\
d \pi_{1,1} \approx \frac{\partial \pi_{1,1}}{\partial v_{1}} d v_{1}+\frac{\partial \pi_{1,1}}{\partial c_{1}} d c_{1}=q^{c}\left[\frac{\partial p_{1,1}^{*}}{\partial v_{1}} d v_{1}-d c_{1}\right]+\left(1-q^{c}\right)\left[\frac{1+\eta}{1+\eta \lambda} d v_{1}-d c_{1}\right]
\end{gathered}
$$


and

$$
d \pi_{2,2}=0 .
$$

By substituting and re-arranging, we have that $d \pi_{1,1}>d \pi_{2,1}$ as

$$
\begin{gathered}
{\left[q^{c}+\frac{2\left(1-q^{c}\right) \eta(\lambda-1) q^{c}}{1+\eta(\lambda-1)\left(1-q^{c}\right)} \frac{1+\eta}{1+\eta \lambda}+\left(1-q^{c}-\underline{q}\right) \frac{1+\eta}{1+\eta \lambda}-\frac{2 q \eta \eta(\lambda-1)(1-\underline{q})}{1+\eta(\lambda-1) \underline{q}} \frac{1+\eta}{1+\eta \lambda}\right] d v_{1}>(1-\underline{q}) d c_{1}} \\
\Leftrightarrow d v_{1}>d c_{1}
\end{gathered}
$$

where the last inequality follows from $1-\underline{q}=q^{c}$. Similarly, $d \pi_{1,1}>d \pi_{1,2}$ because

$$
\begin{gathered}
{\left[q^{c}+\frac{2\left(1-q^{c}\right) \eta(\lambda-1) q^{c}}{1+\eta(\lambda-1)\left(1-q^{c}\right)} \frac{1+\eta}{1+\eta \lambda}+\left(1-q^{c}\right) \frac{1+\eta}{1+\eta \lambda}-\bar{q}+\frac{2(1-\bar{q}) \eta(\lambda-1) \bar{q}}{1+\eta(\lambda-1)(1-\bar{q})}\right] d v_{1}>(1-\bar{q}) d c_{1}} \\
\Leftrightarrow\left[\frac{2 \eta(\lambda-1) \bar{q}}{1+\eta(\lambda-1)(1-\bar{q})}\left(\frac{2+\eta \lambda+\eta}{1+\eta \lambda}\right)+\frac{1+\eta}{1+\eta \lambda}\right] d v_{1}>d c_{1}
\end{gathered}
$$

where the last inequality follows from $\bar{q}=q^{c}>\frac{1}{2}$ and $d v_{1}>d c_{1}$.

Finally, let's start again from $v_{1}=v_{2}$ and $c_{1}=c_{2}$ and suppose to change $v_{2}$ by $d v_{2}$ and $c_{2}$ by $d c_{2}$ with $d c_{2} \leq d v_{2}<0$ so that $v_{1}-c_{1} \leq v_{2}-c_{2}$. We have

$$
\begin{gathered}
d \pi_{1,2} \approx \frac{\partial \pi_{1,2}}{\partial v_{2}} d v_{2}+\frac{\partial \pi_{1,2}}{\partial c_{2}} d c_{2}=\left[\bar{q} \frac{\partial p_{1,2}^{*}}{\partial v_{2}}+(1-\bar{q}) \frac{1+\eta}{1+\eta \lambda}\right] d v_{2}-(1-\bar{q}) d c_{2} \\
d \pi_{2,1} \approx \frac{\partial \pi_{2,1}}{\partial v_{2}} d v_{2}+\frac{\partial \pi_{2,1}}{\partial c_{2}} d c_{2}=(1-\underline{q}) \frac{\partial p_{2,1}^{*}}{\partial v_{2}} d v_{2}-(1-\underline{q}) d c_{2} \\
d \pi_{1,1}=0
\end{gathered}
$$

and

$$
d \pi_{2,2} \approx \frac{\partial \pi_{2,2}}{\partial v_{2}} d v_{2}+\frac{\partial \pi_{2,2}}{\partial c_{2}} d c_{2}=\left[q^{c} \frac{\partial p_{2,2}^{*}}{\partial v_{2}}+\left(1-q^{c}\right) \frac{1+\eta}{1+\eta \lambda}\right] d v_{2}-d c_{2}
$$

By substituting and re-arranging, we have that $d \pi_{2,1}>d \pi_{1,2}$ as

$$
\begin{aligned}
(1-\underline{q})\left(d v_{2}-d c_{2}\right) & >(1-\bar{q})\left\{\left[\frac{2 \eta(\lambda-1) \bar{q}}{1+\eta(\lambda-1)(1-\bar{q})} \frac{2+\eta \lambda+\eta}{1+\eta \lambda}+\frac{1+\eta}{1+\eta \lambda}\right] d v_{2}-d c_{2}\right\} \\
& \Leftarrow \frac{2 \eta(\lambda-1) \bar{q}}{1+\eta(\lambda-1)(1-\bar{q})} \frac{2+\eta \lambda+\eta}{1+\eta \lambda}+\frac{1+\eta}{1+\eta \lambda}>1
\end{aligned}
$$

where the last inequality follows from $\bar{q}=1-\underline{q}>\frac{1}{2}$.

Finally, we have that $d \pi_{2,1} \geq d \pi_{2,2}$ if and only if

$$
\begin{aligned}
(1-\underline{q})\left(d v_{2}-d c_{2}\right) \geq & q^{c}\left[1+\frac{2\left(1-q^{c}\right) \eta(\lambda-1)}{1+\eta(\lambda-1)\left(1-q^{c}\right)} \frac{1+\eta}{1+\eta \lambda}\right] d v_{2}+\left(1-q^{c}\right) \frac{1+\eta}{1+\eta \lambda} d v_{2}-d c_{2} \\
& \Leftrightarrow d c_{2} \geq \frac{1+\eta}{1+\eta \lambda}\left[\frac{2 \eta(\lambda-1) q^{c}}{1+\eta(\lambda-1)\left(1-q^{c}\right)}+1\right] d v_{2}
\end{aligned}
$$

as $q^{c}=1-q$. Notice that, although $d v_{2}-d c_{2}>0$, condition (6) might hold. Then, let $\widetilde{v}_{2}$ be the value of $v_{2}$ for which condition (6) binds. This completes the proof. 


\section{B.2 Heterogeneous Tastes}

In the proof of Proposition 5 we use the following lemma.

Lemma 5 Suppose the seller plays the limited-availability strategy that makes a type-v consumer indifferent between buying only the bargain item and always buying. Then, for types in $\left[v^{l}, v\right)$ the PPE plan is to never buy whereas for types in $\left[v, v^{h}\right]$ the PPE plan is to always buy. Furthermore, a consumer's equilibrium expected utility is weakly increasing in his type.

Proof of Lemma 5: We already know that if a consumer of type $v$ is indifferent between the plan of buying only the bargain and the plan of always buying, then his equilibrium expected utility must be negative as he is paying a price above his valuation and, moreover, he is facing uncertainty over the price. Next, consider the equilibrium expected utility for a consumer with type $\bar{v} \in\left(v, v^{h}\right]$. If he plans to buy only the bargain item, his expected utility in equilibrium equals

$$
q^{*}\left[\bar{v}-p^{\min }(v)\right]-\eta(\lambda-1) q^{*}\left(1-q^{*}\right)\left(\bar{v}+p^{\min }(v)\right) .
$$

Differentiating (7) with respect to $\bar{v}$ yields $q^{*}\left[1-\eta(\lambda-1)\left(1-q^{*}\right)\right]$. On the other hand, if he plans to always buy, his expected utility in equilibrium is

$$
\bar{v}-q^{*} p^{\min }(v)-\left(1-q^{*}\right) p^{*}(v)-\eta(\lambda-1) q^{*}\left(1-q^{*}\right)\left[p^{*}(v)-p^{\min }(v)\right] .
$$

Differentiating (8) with respect to $\bar{v}$ yields 1 . Therefore, all consumers with type $\bar{v} \in\left(v, v^{h}\right]$ prefer the plan to always buy to the plan to buy only the bargain item.

Next, consider the plan of buying only the rip-off item and nothing otherwise. In this case the consumers' equilibrium expected-utility is

$$
\left(1-q^{*}\right)\left[\bar{v}-p^{*}(v)\right]-\eta(\lambda-1) q^{*}\left(1-q^{*}\right)\left[\bar{v}+p^{*}(v)\right] .
$$

It is easy to see that (8) is always larger than (9) as

$$
\bar{v}\left[1+\eta(\lambda-1)\left(1-q^{*}\right)\right]>p^{\min }(v)\left[1-\eta(\lambda-1)\left(1-q^{*}\right)\right]
$$

and therefore we have proved that all consumers with type $\bar{v} \in\left(v, v^{h}\right]$ prefer to always buy.

Last, consider the consumers with type $\underline{v} \in\left[v^{l}, v\right)$. For these types, not buying is a credible plan because $p^{\min }(v)>p^{\min }(\underline{v})$. Therefore, they are going to plan to buy with positive probability only if they can make (weakly) positive utility in expectation. From (7) we have that a consumer's expected utility when planning to buy the bargain item and nothing otherwise is non-decreasing in his own type if and only if $1-\eta(\lambda-1)\left(1-q^{*}\right) \geq 0$. If this condition holds, then as a type- $v$ consumer gets strictly negative utility in equilibrium so would a a type- $\underline{v}$ if he were to plan to buy; therefore, the latter would prefer planning not to buy. This argument does not work when $1-\eta(\lambda-1)\left(1-q^{*}\right)<0$ because in this case a consumer's expected utility is decreasing with his type when he plans to buy only the bargain. However, the utility of a type- $\underline{v}$ consumer when planning to buy only the bargain is equal to

$q^{*}\left[\underline{v}-p_{1}^{\min }(v)\right]-\eta(\lambda-1) q^{*}\left(1-q^{*}\right)\left[\underline{v}+p_{1}^{\min }(v)\right]=q^{*}\left\{\underline{v}-p_{1}^{\min }(v)-\eta(\lambda-1)\left(1-q^{*}\right)\left[\underline{v}+p_{1}^{\min }(v)\right]\right\}$

which is negative for $1-\eta(\lambda-1)\left(1-q^{*}\right)<0$. Therefore, also in this case consumers prefer not to buy. By the same argument, it is easy to see that these consumers would never plan to buy only the rip-off either and this concludes the proof. 
We are now ready to prove Proposition 5 in the text.

Proof of Proposition 5: From Lemma 5 we know that for a given marginal type $v$, types above $v$ plan to always buy and types below $v$ plan to never buy. Then, the problem reduces to a standard monopoly-pricing one where the seller charges an expected price equal to

$$
\left(1-q^{*}\right) p^{*}(v)+q^{*} p^{\min }(v)=\Phi v
$$

where $\Phi \equiv \frac{4-2 \eta^{2}+\eta^{2} \lambda^{2}+4 \lambda \eta+\eta^{2} \lambda-2 \sqrt{2(2+\eta+\eta \lambda)(1+\eta)(1+\eta \lambda-\eta)}}{\eta(\lambda-1)(1+\eta \lambda)}>1$. Let $\widehat{v}$ be the profit-maximizing marginal type. In equilibrium a consumer of type- $v$ attains a positive expected utility if and only if

$$
v \geq q^{*} p^{\min }(\widehat{v})+\left(1-q^{*}\right) p^{*}(\widehat{v})+\eta(\lambda-1) q^{*}\left(1-q^{*}\right)\left[p^{*}(\widehat{v})-p^{\min }(\widehat{v})\right] \equiv v^{s}
$$

and this concludes the proof.

In the proof of Proposition 6 we use the following lemma.

Lemma 6 Fix any $\eta>0$ and $\lambda>1$. The optimal limited-availability scheme is to sell one item at $p_{1}=\frac{1+\eta}{1+\eta \lambda} v_{L}$ and the other one at $p_{2}=v_{L}+\frac{2 q^{*} \eta(\lambda-1)}{1+q^{*} \eta(\lambda-1)} \frac{1+\eta}{1+\eta \lambda} v_{L}$ where

$$
q^{*}=\frac{\sqrt{2(1+\eta)(2+\eta \lambda+\eta)[1+\eta(\lambda-1)]}}{\eta(\lambda-1)(2+\eta \lambda+\eta)}-\frac{1}{\eta(\lambda-1)}
$$

is the degree of availability of the bargain item. Furthermore, $q^{*}<\frac{1}{2}$.

Proof of Lemma 6: For the bargain, $p_{1}=\frac{1+\eta}{1+\eta \lambda} v_{L}$ as this is the highest price that makes $\{\varnothing\}$ not a PE. For $p_{2} \geq p_{1}$ and $q \in(0,1)$, plan $\{1,2\}$ is the PPE for consumers of type $\left(v_{H}, v_{L}\right)$ if and only if

$$
\begin{gathered}
q\left(v_{H}-\frac{1+\eta}{1+\eta \lambda} v_{L}\right)-q(1-q) \eta(\lambda-1)\left(v_{H}+\frac{1+\eta}{1+\eta \lambda} v_{L}\right) \leq \\
-q\left(v_{H}-\frac{1+\eta}{1+\eta \lambda} v_{L}\right)+(1-q)\left(v_{L}-p_{2}\right) \\
-q(1-q) \eta(\lambda-1)\left(v_{H}-v_{L}\right) \\
\Leftrightarrow p_{2} \leq v_{L}+\frac{2 q \eta(\lambda-1)}{1+q \eta(\lambda-1)} \frac{1+\eta}{1+\eta \lambda} v_{L} .
\end{gathered}
$$

Similarly, for consumers of type $\left(v_{L}, v_{H}\right)$ plan $\{1,2\}$ is the PPE if and only if

$$
\begin{gathered}
q\left(v_{L}-\frac{1+\eta}{1+\eta \lambda} v_{L}\right)-q(1-q) \eta(\lambda-1)\left(v_{L}+\frac{1+\eta}{1+\eta \lambda} v_{L}\right) \leq \\
-q\left(v_{L}-\frac{1+\eta}{1+\eta \lambda} v_{L}\right)+(1-q)\left(v_{H}-p_{2}\right) \\
-q(1-q) \eta(\lambda-1)\left(v_{H}-v_{L}\right) \\
-q(1-q) \eta(\lambda-1)\left(p_{2}-\frac{1+\eta}{1+\eta \lambda} v_{L}\right) \\
\Leftrightarrow p_{2} \leq \frac{1-q \eta(\lambda-1)}{1+q \eta(\lambda-1)} v_{H}+\frac{2 q \eta(\lambda-1)}{1+q \eta(\lambda-1)} \frac{2+\eta \lambda+\eta}{1+\eta \lambda} v_{L}
\end{gathered}
$$

It is easy to verify that the right-hand-side of (11) always exceeds the right-hand-side of (10). Hence, 
in order to induce both types of consumers to select plan $\{1,2\}$, the seller must price item 2 at

$$
p_{2}(q)=v_{L}+\frac{2 q \eta(\lambda-1)}{1+q \eta(\lambda-1)} \frac{1+\eta}{1+\eta \lambda} v_{L}
$$

The seller then chooses the degree of availability of item 1 that solves the following program

$$
\max _{q} q p_{1}+(1-q) p_{2}(q)
$$

Taking FOC yields

$$
q^{*}=\frac{\sqrt{2(\eta+1)(\eta+\lambda \eta+2)(-\eta+\lambda \eta+1)}}{\eta(\lambda-1)(\eta+\lambda \eta+2)}-\frac{1}{\eta(\lambda-1)} .
$$

Finally, we have

$$
q^{*} \leq \frac{1}{2} \Leftrightarrow-\eta(\lambda-1)\left(\lambda^{2} \eta^{2}+6 \lambda \eta-\eta^{2}-6 \eta+4\right)<0
$$

which hold for any $\eta>0$ and $\lambda>1$. This concludes the proof.

We can now prove Proposition 6 in the text.

Proof of Proposition 6: By Lemma 6, with a limited-availability scheme, the seller's profit is equal to

$$
\pi^{* *}=q^{*}\left(\frac{1+\eta}{1+\eta \lambda} v_{L}\right)+\left(1-q^{*}\right)\left(v_{L}+\frac{2 q^{*} \eta(\lambda-1)}{1+q^{*} \eta(\lambda-1)} \frac{1+\eta}{1+\eta \lambda} v_{L}\right) .
$$

Substituting for $q^{*}$ and re-arranging yields

$$
\pi^{* *}=\frac{\left(4-2 \eta^{2}+\eta^{2} \lambda^{2}+4 \lambda \eta+\eta^{2} \lambda-2 \sqrt{2(2+\eta+\eta \lambda)(1+\eta)(1+\eta \lambda-\eta)}\right) v_{L}}{\eta(\lambda-1)(1+\eta \lambda)} .
$$

Thus,

$$
\pi^{* *} \geq v_{H} \Leftrightarrow \frac{v_{L}}{v_{H}}>\frac{\eta(\lambda-1)(1+\eta \lambda)}{4-2 \eta^{2}+\eta^{2} \lambda^{2}+4 \lambda \eta+\eta^{2} \lambda-2 \sqrt{2(2+\eta+\eta \lambda)(1+\eta)(1+\eta \lambda-\eta)}} .
$$

This concludes the proof.

\section{B.3 Optimistic Consumers}

Suppose that when the seller announces a degree of availability $q$ for a bargain, consumers are overly optimistic about their chance of getting a deal and think they will get the bargain with probability $\widetilde{q}=\min \{\chi q, 1\}$, where $\chi>1$ parametrizes the degree of consumers' optimism. The seller knows $\chi$, but cannot be held liable for the difference between perceived and actual availability; however, she cannot reduce product availability below the level $q$ that she announces. Consumers still select a PPE purchasing plan, but they base their decisions and payoffs' comparison on the biased beliefs $\widetilde{q}$.

For simplicity, let the products be perfect substitutes $\left(v_{1}=v_{2}=v>0\right)$ and assume marginal cost is zero for both products. As a normalization, let item 1 be the bargain and denote by $\widehat{q}$ its profitmaximizing degree of availability when consumers have rational expectations $(\chi=1)$. At first one could be tempted to guess that with naïve consumers, the seller would always choose a lower degree of availability for the bargain item, compared to the rational case. After all, the seller can just announce 
$q=\frac{\widehat{q}}{\chi}$, inducing the same attachment effect as with rational consumers but actually selling the bargain less often and hence making even higher profits. Yet, this intuition is incomplete. To see why, notice that for given $q$ and $p_{1}$, the highest price the monopolist can charge for item 2 to induce the consumers to select plan $\{1,2\}$ is $p_{2}^{*}\left(q, p_{1}\right)=v+\left[\frac{2 \eta(\lambda-1) \chi q}{1+\eta(\lambda-1) \chi q}\right]$. It is easy to see that

$$
\frac{\partial^{2} p_{2}^{*}\left(q, p_{1}\right)}{\partial \chi \partial q}>0 \Leftrightarrow 1-q \chi \eta(\lambda-1)>0,
$$

implying that if $\chi$ is small, the marginal gain from raising $q$ is higher when consumers are optimistic. The monopolist will then choose the degree of availability and price for item 1 that solve:

$$
\max _{q, p_{1}} \tilde{\pi}=q p_{1}+(1-q) p_{2}^{*}\left(q, p_{1}\right) .
$$

Let $q_{\chi}\left(p_{1}\right)$ be the solution to this maximization problem. The following proposition characterizes the seller's profit-maximizing strategy.

Proposition 7 Fix any $\eta>0$ and $\lambda>1$. There exists a $\tilde{\chi}$ such that the seller's profit-maximizing strategy is as follows:

(i) if $\chi<\tilde{\chi}$, she announces a degree of availability for the bargain equal to $q_{\chi}\left(p_{1}^{\min }\right)$, and prices $p_{1}^{\min }$ and $p_{2}^{*}\left(q_{\chi}\left(p_{1}^{\min }\right), p_{1}^{\min }\right)$;

(ii) if $\chi \geq \tilde{\chi}$, she announces a degree of availability for the bargain equal to $q_{\chi}=\frac{1}{\chi}$ and prices $v$ and $p_{2}^{*}=v\left(1+\frac{\eta(\lambda-1)}{1+\eta \lambda}\right)$.

Furthermore, the seller's expected profit is strictly greater than $v$.

Proof of Proposition 7: Suppose $p_{1}=p_{1}^{\min } \equiv \frac{1+\eta}{1+\eta \lambda} v$. Then, $\{\varnothing\}$ is not a credible plan for consumers and for a given $q$ their perceived expected utility under plan $\{1, \varnothing\}$ is

$$
E U[\{1, \varnothing\} \mid\{1, \varnothing\}]=\widetilde{q}\left(v-p_{1}^{\min }\right)-\widetilde{q}(1-\widetilde{q}) \eta(\lambda-1)\left(v+p_{1}^{\min }\right)
$$

where $\widetilde{q}=\chi q>q$. Consumers will be indifferent between the above plan and plan $\{1,2\}$ if and only if

$$
p_{2} \leq v+\left[\frac{2 \eta(\lambda-1) \widetilde{q}}{1+\eta(\lambda-1) \widetilde{q}}\right] p_{1}^{\min } \equiv p_{2}^{*}
$$

This pair of prices provides the seller with profits equal to

$$
q p_{1}^{\min }+(1-q) p_{2}^{*}
$$

The above expression is maximized at

$$
q_{\chi}=\frac{\sqrt{2(\eta+1)(\eta+\lambda \eta+2)(-\chi \eta+\lambda \chi \eta+1)}}{\chi \eta(\lambda-1)(\eta+\lambda \eta+2)}-\frac{1}{\chi \eta(\lambda-1)} .
$$

Notice that expression (12) is a continuous function of $\widetilde{q}$, and its value is 0 for $\widetilde{q}=0$ and $v-p_{1}^{\min }>0$ for $\widetilde{q}=1$. Furthermore, its derivative evaluated at $\widetilde{q}=0$ is equal to

$$
v-p_{1}^{\min }-\eta(\lambda-1)\left(v+p_{1}^{\min }\right)=-\frac{\eta(\lambda-1)}{1+\eta \lambda}(1+\eta+\eta \lambda) v<0 .
$$


Therefore, expression (12) must have another zero for $\widetilde{q} \in(0,1)$ :

$$
\begin{aligned}
0 & =v-p_{1}^{\min }-(1-\widetilde{q}) \eta(\lambda-1)\left(v+p_{1}^{\min }\right) \Leftrightarrow \chi q_{\chi}=\frac{1+\eta+\eta \lambda}{2+\eta+\eta \lambda} \\
& \Leftrightarrow \quad \chi=\frac{\eta^{3} \lambda^{3}+\eta^{3} \lambda^{2}+4 \eta^{2} \lambda^{2}-\eta^{3} \lambda+4 \eta^{2} \lambda+8 \eta \lambda-\eta^{3}+6 \eta+6}{2(1+\eta)(2+\eta+\eta \lambda)} \equiv \widetilde{\chi} .
\end{aligned}
$$

Hence, for $\chi \geq \tilde{\chi}$ consumers' perceived expected utility is zero. But then, the seller can set $q=\frac{1}{\chi}$ and $p_{1}=v$ without affecting consumers' perceived expected utility. In this case, because consumers believe they will buy item 1 at price $v$ for sure, the highest price they are willing to pay ex-post for item 2 is $p_{2}=v\left[1+\frac{\eta(\lambda-1)}{1+\eta \lambda}\right]$. It is easy to see that this scheme provides the seller with higher profits as consumers' realized consumption utility is at most zero in any contingency.

The first implication of Proposition 7 is that the monopolist profit displays a discontinuity at $\tilde{\chi}$. The intuition is as follows. For moderate levels of consumers' optimism, the seller's profit-maximization problem is similar to the one with rational consumers: she chooses the highest price for the bargain that makes $\{\varnothing\}$ not a credible plan and a price for the rip-off such that consumers ex-ante are (perceive to be) indifferent between plans $\{1, \varnothing\}$ and $\{1,2\}$. Then, she announces a degree of availability for the bargain that trades off the gains from exploiting the attachment effect with those from selling the rip-off more often than the bargain. Hence, except for the fact that consumers believe to be more likely to make a deal than they actually are, the seller's profit-maximizing limited-availability scheme is qualitatively similar to the one derived in Section 4. Things are different, however, when consumers are very optimistic. For $\chi=\tilde{\chi}$ we have that:

$$
\widetilde{q}\left(v-p_{1}^{\min }\right)-\widetilde{q}(1-\widetilde{q}) \eta(\lambda-1)\left(v+p_{1}^{\min }\right)=0,
$$

where $\widetilde{q}=q_{\tilde{\chi}}\left(p_{1}^{\min }\right)$. That is, $\tilde{\chi}$ is the lowest degree of optimism for which, if the seller uses the scheme in part (i) of Proposition 7, consumers perceive their expected utility to be non-negative. In this case, the seller does not need to offer a tempting deal on item 1 to make $\{\varnothing\}$ not credible; instead, she can announce $q_{\chi}=\frac{1}{\chi}$, inducing consumers to believe that they will find item 1 available for sure, and price item 1 at its intrinsic value and item 2 at the highest price consumers are willing to pay ex-post. So at $\chi=\tilde{\chi}$, the degree of availability of the bargain and the prices jump up and so does the seller's profit.

\section{Partial Commitment}

While retailers frequently advertise their good deals, it is rather uncommon to see a store publicizing its high prices. Therefore, consistently with this observation about stores' advertising patterns, in this section I assume that in period 0 the seller commits only to the price of the bargain $p_{i}^{\min }, i=1,2$, and its degree of availability. In this case, consumers form rational expectations about the price of the item that is not publicly advertised.

Suppose the seller uses item 1 as the bargain by announcing that she has $q$ units of it available for sale at price $p_{1}^{\min }$. Once at the store, a buyer who had planned to buy item 1 if available and item 2 otherwise will follow his plan and buy item 2 when this is the only item left in the store if

$$
\begin{gathered}
U\left[\left(v_{2}, p_{2}\right) \mid\{1,2\}\right] \geq U[(0,0) \mid\{1,2\}] \\
\Leftrightarrow \quad p_{2} \leq \frac{(1+\eta \lambda) v_{2}+\eta(\lambda-1) q\left(\frac{1+\eta}{1+\eta \lambda}\right) v_{1}}{1+\eta \lambda q+\eta(1-q)} .
\end{gathered}
$$


Notice that this price is higher than the one we found under full commitment because now the price of the rip-off is the highest price consumers are willing to pay ex-post. However, for the consumers to be willing to make plan $\{1,2\}$ to begin with, the seller's announced degree of availability for item 1 must be such that

$$
E U[\{1,2\} \mid\{1,2\}] \geq E U[\{1, \varnothing\} \mid\{1, \varnothing\}] .
$$

To have an optimum for the seller both conditions (13) and (14) have to bind, defining a system of two non-linear equations in $q$ and $p_{2}$. The relevant solution is

$$
\begin{aligned}
p_{2}^{*} & =\frac{v_{1}(1+\eta)(1+2 \eta)+v_{2}(1+\eta \lambda)(1+\eta+\eta \lambda)-\sqrt{Y}}{2 \eta(1+\eta \lambda)} \\
\underline{q} & =\frac{v_{2} \lambda(1+\eta \lambda)-\frac{1+\eta \lambda}{2 \eta(1+\eta \lambda)}\left[v_{1}(1+\eta)(1+2 \eta)+v_{2}(1+\eta \lambda)(1+\eta+\eta \lambda)-\sqrt{Y}\right]}{v_{1}(1+\eta)(\lambda-1)+v_{2}(1+\eta \lambda)(\lambda-1)}
\end{aligned}
$$

where

$Y \equiv v_{1}^{2}(1+\eta)^{2}(2 \eta+1)^{2}+v_{2}^{2}(1-\eta+\eta \lambda)^{2}(1+\eta \lambda)^{2}-2 v_{1} v_{2}(1+\eta)(1+\eta \lambda)\left(-\eta-2 \eta^{2}-\eta \lambda+2 \eta^{2} \lambda-1\right)$

Similarly, if the goods are close substitutes and the seller uses item 2 as the bargain, degree of availability of item 1 and its price are

$$
\begin{aligned}
p_{1}^{*}= & \frac{v_{1} \eta(\lambda-1)(1+\eta \lambda)+v_{2}(1+2 \eta)(2+\eta+\lambda \eta)-\sqrt{Z}}{2 \eta(1+\eta \lambda)} \\
\bar{q}= & \frac{v_{2}\left(2 \lambda-\eta-2 \eta^{2}-\eta \lambda-2 \eta^{2} \lambda+\eta \lambda^{2}-2\right)-v_{1} \lambda\left(\eta-\eta^{2}+\eta \lambda+\eta^{2} \lambda+1\right)}{v_{2}(\lambda-1)(\eta+\lambda \eta+2)} \\
& +\frac{\frac{1+\eta \lambda}{2 \eta(1+\eta \lambda)}\left[v_{1} \eta(\lambda-1)(1+\eta \lambda)+v_{2}(1+2 \eta)(2+\eta+\eta \lambda)-\sqrt{Z}\right]}{v_{2}(\lambda-1)(\eta+\eta \lambda+2)}
\end{aligned}
$$

where

$Z \equiv v_{1}^{2} \eta^{2}(1+\lambda)^{2}(1+\eta \lambda)^{2}+v_{2}^{2}(1+2 \eta)^{2}(2+\eta+\lambda \eta)^{2}-2 \eta v_{1} v_{2}(-\lambda+2 \eta+2 \eta \lambda+3)(1+\eta \lambda)(2+\eta+\eta \lambda)$

Compared to when she is able to commit in advance to both prices, now the price of the rip-off is higher but the degree of availability of the bargain is higher as well. Intuitively, as the consumers anticipate that she will charge a higher price for the rip-off, the seller must compensate them with a higher ex-ante chance of making a deal. Thus, given both prices, the seller is not choosing the degree of availability that maximizes her profits. This is because by not committing in advance to the price of the rip-off, the seller must use the degree of availability of the bargain to induce the consumers to select plan $\{1,2\}$ (or $\{2,1\}$ ). Furthermore, the optimal degree of availability with full commitment takes into account also the difference in the marginal costs of the two items, whereas with partial commitment it does not. Therefore, the seller's profits are lower when she cannot commit to both prices.

Unfortunately, in this case it is hard to obtain a full characterization, like the one in Proposition 1, to exactly pin down the conditions for when a limited-availability scheme is profit-maximizing. Nevertheless, such a strategy can be profit-maximizing as the following example shows.

Example 1 Let $v_{1}=250, v_{2}=230, c_{1}=20$ and $c_{2}=10$. If the seller produces only one good, then she would produce item 1 and price it at $p_{1}=250$, obtaining a profit of 230. Let $\eta=1$ and $\lambda=2$ and suppose the seller uses item 1 as a bargain by pricing it at $p_{1}^{\min }=\frac{500}{3}$. In this case the seller will 
also commit to sell $\underline{q}=\frac{2}{119} \sqrt{3459}-\frac{75}{119}$ units of item 1 and will price item 2 at $p_{2}^{*}=710-\frac{20}{3} \sqrt{3459}$, obtaining a profit of 250.15 .

Moreover, as example 1 shows, the seller might prefer to use the superior item as the bargain, exactly for the same reason as in the analysis with full commitment.

\section{Relaxing Assumption 2}

The analysis in Section 4 of the main text is carried out under the assumption that $\frac{v_{2}}{v_{1}}>\max \left\{\frac{1+\eta \lambda}{2+\eta \lambda+\eta}, \frac{1+\eta}{1+\eta \lambda}\right\}$. This ensures that (i) the price of the superior product (item 1), when this is the rip-off, is higher than $v_{1}$ and (ii) that the price of the rip-off is always higher than the price of the bargain, even when the inferior product (item 2) is used as the rip-off. More precisely,

$$
\frac{v_{2}}{v_{1}}>\frac{1+\eta \lambda}{2+\eta \lambda+\eta} \Leftrightarrow p_{2}^{\min }>v_{1}-v_{2}
$$

is necessary and sufficient for $p_{1}^{*}(q)$ to exceed $v_{1}$ for any $q \in(0,1)$. If this condition is violated, it is never profit-maximizing for the seller to use product 1 as the rip-off item, as shown in the following proposition.

Proposition 8 Let $p_{2}^{\min } \leq v_{1}-v_{2}$. Then, there does not exist a limited-availability scheme, where item 1 is used as a rip-off, yielding a higher profit than the perfect-availability scheme in which the seller supplies only the item with the larger social surplus and price it at its intrinsic value.

Proof of Proposition 8: If the seller uses item 1 as the rip-off, item 2 must be priced at $p_{2}^{\min }$. Let $p_{2}^{\min } \leq v_{1}-v_{2}$. First, notice that if the seller uses item 1 as the rip-off, it must be that $p_{1}>v_{1}$. To see why, suppose, by contradiction, that $p_{1} \leq v_{1}$. The seller's profit is

$$
q\left(p_{1}-c_{1}\right)+(1-q)\left(p_{2}^{\min }-c_{2}\right)
$$

Notice that

$$
p_{1} \leq v_{1} \Rightarrow q\left(p_{1}-c_{1}\right)+(1-q)\left(p_{2}^{\min }-c_{2}\right)<q\left(v_{1}-c_{1}\right)+(1-q)\left(v_{2}-c_{2}\right) \leq v_{1}-c_{1} ;
$$

but then the seller would prefer to choose either $q=1$ or $q=0$. So it must be that $v_{1}<p_{1}$.

Next, recall that the seller must make consumers indifferent between plan $\{2, \varnothing\}$ and plan $\{2,1\}$ :

$$
\begin{gathered}
(1-q)\left(v_{2}-p_{2}^{\min }\right)-q(1-q) \eta(\lambda-1)\left(v_{2}+p_{2}^{\min }\right)= \\
-q\left(v_{1}-p_{1}\right)+(1-q)\left(v_{2}-p_{2}^{\min }\right) \\
-q(1-q) \eta(\lambda-1)\left(v_{1}-v_{2}+p_{1}-p_{2}^{\min }\right) \\
\Leftrightarrow(1-q) \eta(\lambda-1)\left[v_{1}+p_{1}-2\left(v_{2}+p_{2}^{\min }\right)\right]=v_{1}-p_{1} .
\end{gathered}
$$

As the right-hand-side of (15) is negative, it follows that

$$
v_{1}+p_{1}-2\left(v_{2}+p_{2}^{\min }\right)<0 \Leftrightarrow \frac{v_{1}+p_{1}}{2}-v_{2}<p_{2}^{\min }
$$

Condition (16) and the assumption that $p_{2}^{\min } \leq v_{1}-v_{2}$ combined together imply

$$
\frac{v_{1}+p_{1}}{2}-v_{2}<v_{1}-v_{2} \Leftrightarrow p_{1}<v_{1}
$$


The result then follows by reductio ad absurdum.

Similarly, $\frac{v_{2}}{v_{1}}>\frac{1+\eta}{1+\eta \lambda}$ is sufficient to ensure that $p_{2}^{*}(q)$ exceeds $p_{1}^{\min }$ for any $q \in(0,1)$. This condition however is actually stronger than what we need. The necessary and sufficient condition for $p_{2}^{*}(q)$ to exceed $p_{1}^{\min }$ for any $q \in(0,1)$ is

$$
v_{2}>\frac{\sqrt{v_{1}(1+\eta)\left\{2\left(c_{1}-c_{2}\right)(1+\eta \lambda)[1+\eta(\lambda-1)]+v_{1}(1+\eta)\right\}}-\eta(\lambda-1)(1+\eta) v_{1}}{(1+\eta \lambda)[1+\eta(\lambda-1)]} .33
$$

If condition (17) is violated, then $p_{2}^{*}(q) \leq p_{1}^{\min }$. In other words, the difference $v_{1}-v_{2}$ is so large that it is impossible for the seller to price the inferior product higher than the superior one. Nevertheless, there exists a limited-availability scheme in which item 2 is used as the rip-off.

Lemma 7 If the seller uses item 1 as a bargain (i.e., $p_{1}=p_{1}^{\min }$ ), then its degree of availability is

$$
q^{*}=\frac{p_{2}-v_{2}}{\eta(\lambda-1)\left(p_{2}+v_{2}\right)}
$$

and the optimal price for item 2 is

$$
p_{2}=\min \left\{p_{2}^{\max }, p_{1}^{\min }\right\}
$$

where $p_{2}^{\max } \equiv \frac{1+\eta \lambda}{1+\eta} v_{2}$. Furthermore, $q^{*}<\frac{1}{2}$.

Proof of Lemma 7: Let item 1 be the bargain item, so that $p_{1}=p_{1}^{\text {min }}$, and suppose $p_{2} \leq p_{1}$. Let $q \in(0,1)$ be the degree of availability of item 1 , and suppose consumers select plan $\{1,2\}$. If item 2 is the only product left in the store, a consumer will follow his plan and buy if

$$
\begin{gathered}
U\left[\left(v_{2}, p_{2}\right) \mid\{1,2\}\right] \geq U[(0,0) \mid\{1,2\}] \\
\Leftrightarrow v_{2}-p_{2}-q \eta \lambda\left(v_{1}-v_{2}\right)+q \eta\left(p_{1}^{\min }-p_{2}\right) \geq-q \eta \lambda v_{1}-(1-q) \eta \lambda v_{2}+q \eta p_{1}^{\min }+(1-q) \eta p_{2} \\
\Leftrightarrow p_{2} \leq \frac{1+\eta \lambda}{1+\eta} v_{2} \equiv p_{2}^{\max } .
\end{gathered}
$$

However, we assumed that $p_{2} \leq p_{1}$. Hence, if

$$
p_{2}^{\max }>p_{1}^{\min } \Leftrightarrow v_{2}>\left(\frac{1+\eta}{1+\eta \lambda}\right)^{2} v_{1}
$$

then the highest price that the seller can charge for good 2 is $p_{1}^{\min }$.

As the seller is charging the highest price for good 2 that consumers are willing to pay ex-post, she must choose the $q$ that makes consumers ex-ante indifferent between plan $\{1, \varnothing\}$ and plan $\{1,2\}$.

Suppose first that $p_{2}=p_{2}^{\max }$; we have

$$
\begin{aligned}
q\left(v_{1}-p_{1}^{\min }\right)-q(1-q) \eta(\lambda-1)\left(v_{1}+p_{1}^{\min }\right)= & q\left(v_{1}-p_{1}^{\min }\right)+(1-q)\left(v_{2}-p_{2}^{\max }\right) \\
& -q(1-q) \eta(\lambda-1)\left(v_{1}-v_{2}+p_{1}^{\min }-p_{2}^{\max }\right)
\end{aligned}
$$

${ }^{33}$ Notice that if $c_{1}=c_{2}$, then condition (17) reduces to

$$
v_{2}>\frac{(1+\eta)[1-\eta(\lambda-1)] v_{1}}{(1+\eta \lambda)[1+\eta(\lambda-1)]}
$$

which is trivially satisifed if $\eta(\lambda-1) \geq 1$. 


$$
\Leftrightarrow q=\frac{p_{2}^{\max }-v_{2}}{\eta(\lambda-1)\left(p_{2}^{\max }+v_{2}\right)} .
$$

Next, suppose that $p_{2}=p_{1}^{\min }$; we have

$$
\begin{aligned}
& q\left(v_{1}-p_{1}^{\min }\right)-q(1-q) \eta(\lambda-1)\left(v_{1}+p_{1}^{\min }\right)=q\left(v_{1}-p_{1}^{\min }\right)+(1-q)\left(v_{2}-p_{1}^{\min }\right) \\
& -q(1-q) \eta(\lambda-1)\left(v_{1}-v_{2}\right) \\
& \Leftrightarrow q=\frac{p_{1}^{\min }-v_{2}}{\eta(\lambda-1)\left(p_{1}^{\min }+v_{2}\right)} .
\end{aligned}
$$

Therefore, in either case we have

$$
q=\frac{p_{2}-v_{2}}{\eta(\lambda-1)\left(p_{2}+v_{2}\right)} \equiv q^{*} .
$$

Finally, notice that

$$
\frac{p_{2}^{\max }-v_{2}}{\eta(\lambda-1)\left(p_{2}^{\max }+v_{2}\right)}>\frac{p_{1}^{\min }-v_{2}}{\eta(\lambda-1)\left(p_{1}^{\min }+v_{2}\right)} \Leftrightarrow p_{2}^{\max }>p_{1}^{\min }
$$

and

$$
\frac{p_{2}^{\max }-v_{2}}{\eta(\lambda-1)\left(p_{2}^{\max }+v_{2}\right)}=\frac{\frac{1+\eta \lambda}{1+\eta} v_{2}-v_{2}}{\eta(\lambda-1)\left(\frac{1+\eta \lambda}{1+\eta} v_{2}+v_{2}\right)}=\frac{1}{2+\eta+\eta \lambda}<\frac{1}{2}
$$

for any $\eta>0$ and $\lambda>1$. Hence, $q^{*}<\frac{1}{2}$.

Thus, when the products are not close substitutes the seller prices them close to one another in order to mitigate consumer's expected gain-loss disutility. Furthermore, if $p_{2}^{\max } \geq p_{1}^{\min }$ the optimal limitedavailability strategy entails flat pricing so that the consumers do not face any uncertainty in price. The following proposition delivers necessary and sufficient conditions for when such a limited-availability scheme is profit-maximizing.

Proposition 9 Fix any $\eta>0$ and $\lambda>1$. The seller's profit-maximizing strategy is as follows:

(i) for $\frac{v_{2}}{v_{1}}<\left(\frac{1+\eta}{1+\eta \lambda}\right)^{2}$ there exists a $\alpha\left(v_{2}, c_{1}, c_{2}, \eta, \lambda\right)$ such that a limited-availability scheme with $q=q^{*}$, $p_{1}=p_{1}^{\min }$ and $p_{2}=p_{2}^{\max }$ is profit-maximizing if and only if $v_{1} \leq \alpha$.

(ii) for $\frac{v_{2}}{v_{1}} \geq\left(\frac{1+\eta}{1+\eta \lambda}\right)^{2}$ there exists a $\rho\left(v_{1}, c_{1}, c_{2}, \eta, \lambda\right)$ such that a limited-availability scheme with $q=q^{*}$, $p_{1}=p_{1}^{\min }$ and $p_{2}=p_{1}^{\min }$ is profit-maximizing if and only if $v_{2} \geq \rho$.

Furthermore, $\pi\left(p_{1}, p_{2}, q ; c_{1}, c_{2}\right)>v_{1}-c_{1}$ if both items are supplied.

Proof of Proposition 9: If $\frac{v_{2}}{v_{1}}<\left(\frac{1+\eta}{1+\eta \lambda}\right)^{2}$, the rip-off price for product 2 is equal to $p_{2}^{\max }$ and the seller will use a limited-availability scheme if and only if

$$
q^{*}\left(p_{1}^{\min }-c_{1}\right)+\left(1-q^{*}\right)\left(p_{2}^{\max }-c_{2}\right) \geq v_{1}-c_{1} .
$$

Substituting for $q^{*}, p_{1}^{\min }$ and $p_{2}^{\max }$, and solving for $v_{1}$ yields

$$
v_{1} \leq \frac{1+\eta+2 \eta \lambda+\eta^{2} \lambda+\eta^{2} \lambda^{2}}{1+3 \eta \lambda+\eta^{2} \lambda+\eta^{2} \lambda^{2}}\left(c_{1}-c_{2}+\frac{1+\eta \lambda}{1+\eta} v_{2}\right) \equiv \alpha\left(v_{2}, c_{1}, c_{2}, \eta, \lambda\right) .
$$


On the other hand, if $\frac{v_{2}}{v_{1}} \geq\left(\frac{1+\eta}{1+\eta \lambda}\right)^{2}$ the rip-off price for product 2 is equal to $p_{1}^{\text {min }}$ and the seller will use a limited-availability scheme if and only if

$$
q^{*}\left(p_{1}^{\min }-c_{1}\right)+\left(1-q^{*}\right)\left(p_{1}^{\min }-c_{2}\right) \geq v_{1}-c_{1}
$$

Substituting for $q^{*}$ and $p_{1}^{\min }$, and solving for $v_{1}$ yields

$$
v_{2} \geq \frac{\left(c_{1}-c_{2}\right)\left[1+\eta\left(\eta \lambda-\eta \lambda^{2}+1\right)\right]+\eta^{2}(\lambda-1)^{2} v_{1}}{\left(c_{1}-c_{2}\right)\left[1-\eta\left(2 \lambda-\eta \lambda+\eta \lambda^{2}+1\right)\right]-\eta^{2}(\lambda-1)^{2} v_{1}} \frac{1+\eta}{1+\eta \lambda} v_{1} \equiv \rho\left(v_{1}, c_{1}, c_{2}, \eta, \lambda\right) .
$$

To conclude the proof, notice that the seller's profit under perfect availability equals $v_{1}-c_{1}$. As she would choose a different option only if this provides her with at least as much, it follows that $\pi>v_{1}-c_{1}$ if both items are supplied. 